\title{
Litoquímica, Geocronologia U-Pb e Geologia Isotópica (Sr-Nd-Pb) das Rochas Graníticas dos Batólitos Cunhaporanga e Três Córregos na Porção Sul do Cinturão Ribeira, Estado do Paraná
}

\author{
Hélcio José dos Prazeres Filho ${ }^{1}$ (prazeres@usp.br), O ssama Mohamed Harara ${ }^{1}$, Miguel Angelo Stipp Basei ${ }^{2}$ \\ Cláudia Regina Passarelli³, O swaldo Siga Jr.2 \\ ${ }^{1}$ Programa de Pós-Graduação em Geoquímica e Geotectônica - Instituto de Geociências - USP \\ R. do Lago 562, CEP 05508-080, São Paulo, SP, BRA \\ ${ }^{2}$ Departamento de Mineralogia e Geotectônica - Instituto de Geociências - USP, São Paulo, SP, BRA \\ ${ }^{3}$ Centro de Pesquisas Geocronológicas - Instituto de Geociências - USP, São Paulo, SP, BRA
}

Palavras-chave: Cinturão Ribeira, batólitos graníticos, geocronologia, geoquímica isotópica.

\section{RESUMO}

Durante a evolução da porção sul do Cinturão Ribeira no Estado do Paraná, o Ciclo Brasiliano-Pan Africano foi responsável pela geração de um grande volume de rochas graníticas com destaque para os batólitos Cunhaporanga (BCP) e Três Córregos (BTC). Estudos litoquímicos e isotópicos revelaram a existência de tipos graníticos distintos entre dois batólitos e internamente aos mesmos, definidos por unidades graníticas. A principal diferença entre os dois batólitos está no comportamento dos álcalis com o BCP, a NW mais potássico e o BTC, a SE mais sódico. Os dados isotópicos mostram claramente a participação de fontes infracrustais distintas de longa residência crustal, evidenciadas pelos isótopos de $\mathrm{Pb}$ em $\mathrm{K}$-feldspato, pelos valores negativos de $\mathcal{E}_{\mathrm{Nd}}(-11 \mathrm{a}-13$ para o BCP e -17 a -19 para o BTC) e pelas idades TDM (1,8 a 2,0 Ga para o BCP e 2,2 a 2,4 Ga para o BTC). Estas fontes estariam situadas em uma crosta continental paleoproterozóica com a participação de fontes mantélicas e supracrustais na gênese das rochas graníticas do BCP e BTC. A Unidade Ribeirão Butiá do BCP e as Unidades Arrieiros e Paina do BTC estão representadas predominantemente por monzogranitos e granodioritos e raros tonalitos, metaluminosos, cálcio-alcalinos de alto a médio K, formados entre 630 a $620 \mathrm{Ma}$ em ambiente de margem continental ativa. As Unidades Piraí do Sul e Santa Rita do BCP são constituídas por monzogranitos fracamente peraluminosos, de alto K e as Unidades São Sebastião e Conceição do BTC são constituídas respectivamente por quartzo-monzonitos e monzo a sienogranitos fracamente metaluminosos, de alto K. Estas unidades foram formadas em ambiente sin- a tardi-colisional entre 620 e 590 Ma.

Keywords: Ribeira belt, granitic batholiths, geochronology, isotopic geochemistry.

\section{ABSTRACT}

During evolution of the southern part of the Ribeira Belt in Paraná State, the Brasiliano-Pan-African Cycle was responsible for the generation of a large volume of granitic rocks among which the Cunhaporanga (BCP) and Três Córregos (BTC) batholiths stand out. Studies of rock chemistry and isotopic compositions show that differences exist both between and within the batholiths. The main difference between the batholiths is in the behaviour of the alkalies. The BCP is more potassic, while the BTC is more sodic. The isotopic data clearly show the participation of different lower crustal sources with long crustal residence times, given by the isotopic composition of $\mathrm{Pb}$ in $\mathrm{K}$-feldspar, by the negative values of $\boldsymbol{\varepsilon}_{\mathrm{Nd}}(-11$ to -13 for BCP and -17 to -19 for BTC), and by the model $\mathrm{Nd} \mathrm{T}_{\mathrm{DM}}$ ages (1.8 - 2.0 Ga for BCP and $2.2-2.4 \mathrm{Ga}$ for BTC). These sources are situated in Paleoproterozoic continental crust, and different proportions of mantle and crustal contributions are involved in the genesis of the BCP and BTC granites. The Ribeirão Butiá Unit of the BCP and the Arrieiros and Paina units of the BTC are mainly composed of monzogranite and granodiorite with rare tonalite, comprising metaluminous, medium- to high-K calc-alkaline rocks formed between 630 and $620 \mathrm{Ma}$ at an active continental margin. The Piraí do Sul and Santa Rita units of the BCP are formed by slightly peraluminous, high-K monzogranite, while the São Sebastião and Conceição units of the BTC are composed of high-K, slightly metaluminous quartz monzonite and monzo- to syenogranite, respectively. These units were formed under a syn- to late-collisional regime between 620 and 590 Ma. 


\section{IN TRO DUÇÃO}

As diferentes unidades magmáticas e metamórficas neoproterozóicas a eopaleozóicas da porção sudeste e sul brasileira são produtos de diversas acresções de fragmentos litosféricos continentais. Este evento orogenético conhecido como Ciclo Brasiliano-Pan Africano, está bem caracterizado na porção leste da Plataforma Sul-Americana e está representado por cinturões móveis neoproterozóicos, entre os quais destaca-se o Cinturão Ribeira, desenvolvido marginalmente a massas continentais arqueanas/paleoproterozóicas, durante a construção do Supercontinente Gondwana (Figura 1A).

Nas regiões sudeste e sul brasileira são reconhecidos três principais cinturões graníticos: Pelotas-Florianópolis (Basei, 2000), Piên-Mandirituba (Harara, 2001) e Cunhaporanga-Três Córregos-Agudos Grandes (Guimarães, 2000; Prazeres Filho, 2000; Prazeres Filho et al., 2001; Janasi et al., 2001). Os recentes estudos geológicos realizados por estes autores vêm contribuindo para o melhor entendimento da petrologia e da cronologia do magmatismo granítico e têm permitido melhorias na compreensão da evolução geológica do segmento centro-sul da Província Mantiqueira.

As rochas graníticas são os principais produtos em margens continentais ativas (regiões de subducções e colisões) e em regiões intraplaca dos orógenos, e guardam como tal, importantes informações petrológicas que sinalizam suas fontes e seus ambientes geotectônicos formadores.

O principal objetivo deste trabalho é a investigação petrológica e geocronológica dos principais componentes graníticos dos Batólitos Cunhaporanga e Três Córregos no Estado do Paraná. Esta investigação foi baseada em estudos petrográficos, litoquímicos, geocronológicos (U-Pb em zircão) e isotópicos ( $\mathrm{Sr}$ e $\mathrm{Nd}$ em rocha total e $\mathrm{Pb}$ em $\mathrm{K}$-feldspato), que possibilitaram novas inferências petrogenéticas e geotectônicas sobre esses batólitos.

\section{CONTEXTO GEOLÓGICO REGIONAL}

O Cinturão Ribeira (CR) de Almeida et al. (1973) situa-se nos domínios da Província Mantiqueira (Almeida et al., 2000) e pode ser entendido como uma unidade geológica constituída por vários domínios (Figura 1B), com distintas características litológicas, geoquímicas e isotópicas (Cordani \& Sato, 1999; Campos Neto, 2000).

Entre os diferentes domínios tectônicos da porção centro-sul do CR, destaca-se o Domínio Apiaí (DA) que constitui uma faixa com aproximadamente $500 \mathrm{~km}$ de extensão e $100 \mathrm{~km}$ de largura. Os limites tectônicos do DA com as unidades geológicas adjacentes são marcados pelas Zonas de
Cisalhamento Lancinha-Cubatão e Itariri e, a sul está encoberto pelas rochas fanerozóicas da Bacia do Paraná e neoproterozóicas/eopaleozóicas das bacias de Castro e Camarinha (Figuras 1B e C).

O DA é constituído por rochas metavulcanosedimentares (meso a supracrustais) de baixo a médio grau metamórfico. As rochas metamórficas da porção norte do DA estão representadas pelos Grupos Serra do Itaberaba (Juliani et al., 2000) e São Roque (Bergmann, 1988) e as rochas da porção sul pelas seqüências metavulcanosedimentares do Supergrupo Açungui (Fiori, 1990; Campanha \& Sadowski, 1999).

O conhecimento cronológico do principal período de sedimentação e vulcanismo das unidades metavulcanosedimentares do DA é ainda alvo de discussões. Datações preliminares U-Pb (zircão) em rochas metavulcânicas têm apontado idades mesoproterozóicas para as Formações Água Clara, Votuverava e Perau (Reis Neto, 1994; Weber et al. submetido; Basei et al., em preparação) e Grupo Serra do Itaberaba (Juliani et al., 2000), e neoproterozóicas para o Grupo São Roque (Formação Pirapora do Bom Jesus) e Supergrupo Açungui, Formação Iporanga (Hackspacher et al., 2000) e Grupo Itaiacoca (Siga Jr et al., 2001 e 2003). Esses dados são interpretados como os respectivos períodos de sedimentação dessas unidades geológicas.

No âmbito das rochas graníticas do DA, destacam-se os grandes batólitos graníticos como os Batólitos Cunhaporanga, Três Córregos e Agudos Grandes e diversos stocks graníticos tais como Cerne, Piedade, Morro Grande, Varginha, Apiaí, Carambeí, Joaquim Murtinho, Córreas etc (Figura 1C). Para o estudo destas rochas graníticas ressalta-se a importância dos trabalhos de Chiodi Filho et al. (1987), Wernick et al. (1990), Janasi et al. (1990), Gimenez Filho (1993), Reis Neto (1994), Gimenez Filho et al. (1995), Guimarães (1995), Leite (1997), Guimarães \& Ulbrich (1999), Guimarães (2000), Gimenez Filho et al. (2000), Prazeres Filho (2000), Prazeres Filho et al. (2001) e Janasi et al. (2001). Esses trabalhos envolveram mapeamentos geológicos, estudos litoquímicos, geocronológicos, isotópicos, geofísicos e contribuíram para o melhor entendimento petrológico e geocronológico destas rochas graníticas e da evolução geológica da porção sul do CR.

Os batólitos graníticos Cunhaporanga (BCP) e Três Córregos (BTC) estão alojados numa direção preferencial NE-SW, ocorrendo respectivamente na porção setentrional e meridional do Grupo Itaiacoca, cobrindo uma área total de aproximadamente $7000 \mathrm{~km}^{2}$. Os contatos geológicos do BCP com as rochas encaixantes do Grupo Itaiacoca são intrusivos. As relações de contato do BTC com essa mesma unidade geológica são tectônicas e definidas pela Zona de Cisalhamento Itapirapuã e intrusivas com as rochas 


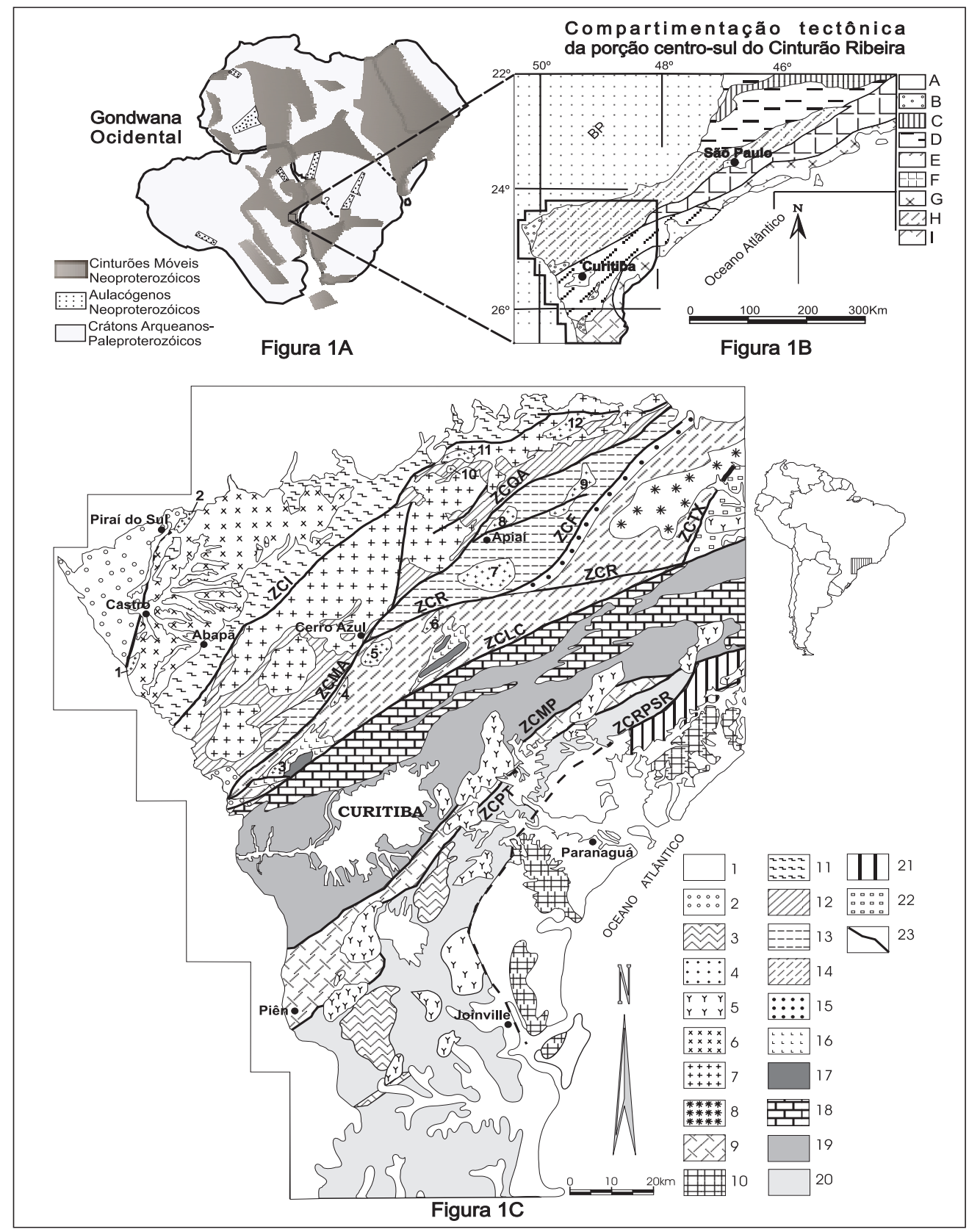

Figura 1. Esboço tectônico e geológico do Pré-Cambriano da porção sul-sudeste brasileira.

1A) Reconstrução paleogeográfica do Gondwana Ocidental (Mod. Unrug, 1996); 1B) Compartimentação tectônica da porção centro-sul do Cinturão Ribeira (Mod. Basei et al., 1992; Campos Neto \& Figueiredo, 1995): A - Cobertura Fanerozóica; B - Bacias neoproterozóicas/ eopaleozóicas; C - Cinturão Alto Rio Grande; D - Domínio Socorro-Guaxupé; E - Domínio Apiaí; F - Domínio Juiz de Fora; G - Domínio Serra do Mar; H - Domínio Curitiba; I - Domínio Luís Alves; 1C) Mapa esquemático das principais unidades geológicas do sul-sudeste brasileiro (Mod. Campanha et al. 1987; Siga Jr., 1995; Basei et al. 1997; Campos Neto, 2000; Harara, 2001): 1 - Cobertura Fanerozóica; 2 - Bacias eopaleozóicas; 3 - Bacias neoproterozóicas; 4 - Stocks graníticos do DA: 1. Carambeí, 2. Joaquim Murtinho, 3. Cerne, 4. Piedade, 5. Morro Grande, 6. Varginha, 7. Itaóca, 8. Apiaí, 9. Espírito Santo, 10. Córreas, 11. Sguário, 12. Capão Bonito; 5 - Granitos alcalinos da Suíte Serra do Mar; Batólitos Graníticos Cálcio Alcalinos Neoproterozóicos: 6 - Batólito Cunhaporanga; 7 - Batólito Três Córregos; 8 - Batólito Agudos Grandes; 9 - Batólito Piên-Mandirituba; 10 - Batólito Paranaguá; Domínio Apiaí - Supergrupo Açungui: 11 - Grupo Itaiacoca; 12 - Formação Água Clara; 13 - Subgrupo Lageado; 14 - Formação Votuverava; 15 - Formação Iporanga; 16 - Formação Perau; 17 - Núcleos granitognáissicos; Domínio Curitiba: 18 - Formação Capirú; 19 - Complexo Atuba; Domínio Luís Alves: 20 - Complexo Granulítico de Santa Catarina; Domínio Serra do Mar: 21 - Seqüência Rio das Cobras; Domínio Juiz de Fora: 22 - Complexo Embu; 23 - Zonas de Cisalhamento (ZC): ZCRPSR - Zona de Cisalhamento Rio Palmital-Serrinha; ZCPT - Piên-Tijucas; ZCMP - Mandirituba-Piraquara; ZCTX - Taxaquara; ZCLC - Lancinha-Cubatão; ZCMA - Morro Agudo; ZCR - Ribeira; ZCF - Figueira; ZCQA - Quarenta Oitava; ZCI - Itapirapuã. 
encaixantes da Formação Água Clara (Figura 1C).

Até a década de oitenta a maioria dos trabalhos de cartografia do $\mathrm{BCP}$ e do BTC foi de reconhecimento regional, sem maiores preocupações em discriminar os principais litotipos ou as diferentes unidades graníticas destes batólitos, porém revelaram a forma geral desses maciços (Fuck et al., 1967; CPRM, 1977). A partir da década de noventa, trabalhos adicionais mostraram a ampla diversidade dos litotipos graníticos destes batólitos com destaque aos trabalhos de Guimarães (1995 e 2000) no BCP e Gimenez Filho (1993) no BTC.

A análise conjunta dos dados petrológicos referentes ao BCP e BTC permite afirmar que se trata de batólitos com grande extensão geográfica, constituídos por uma variedade de rochas graníticas que, em termos de elementos maiores e traços, formam uma sequiência intermediária-félsica, cálcio-alcalina de médio a alto-K, da tipologia I, geradas em ambientes compressionais de margens continentais ativas (arcos magmáticos continentais) (Wernick et al., 1990; Gimenez Filho, 1993; Reis Neto, 1994; Gimenez Filho et al., 2000; Guimarães, 2000; Prazeres Filho, 2000; Prazeres Filho et al., 2001).

Os stocks graníticos que ocorrem intrusivos tanto nas rochas metavulcano-sedimentares do DA (e. g. Passa Três, Cerne, Piedade, Morro Grande, Varginha etc) quanto no BCP e BTC (Joaquim Murtinho, Carambeí, Capão Bonito, Sguário e Córreas) são constituídos por rochas da tipologia A, em ambientes tardi a pós-orogênicos entre 590 a $560 \mathrm{Ma}$ (Leite, 1993; Gimenez Filho, 1993; Guimarães \& Ulbrich, 1999; Guimarães, 2000; Prazeres Filho, 2000; Picanço, 2000; Goraieb, 2001).

Com relação à geocronologia das rochas graníticas do BCP e BTC os dados disponíveis são escassos, contando com pouco mais que 10 datações Rb-Sr (RT) (Gimenez Filho, 1993; Reis Neto, 1994) e 3 datações U-Pb (zircão) (Gimenez Filho et al., 2000). O conjunto desses dados será discutido e comparado com os dados U-Pb (zircão) obtidos neste trabalho.

\section{PETROGRAFIA E GEOCRONOLOGIA U-Pb DAS PRINCIPAIS UNIDADES GRANIITICAS DOS BATÓLITOS CUNHAPORANGA (BCP) E TRÊS CÓRREGOS (BTC)}

A área investigada no presente trabalho (Figura 2) foi estudada por Prazeres Filho (2000) que, a partir da realização de perfis geológicos e com a integração dos trabalhos anteriores, elaborou um mapa geológico (escala 1:250.000) com a representação das principais unidades graníticas do
BCP e do BTC e de seus diferentes litotipos graníticos (Figuras 2 e 3). Esta divisão informal foi baseada nas características petrográficas (mineralogia principal e acessória, tipos de minerais máficos, texturas e estruturas), litoquímicas (elementos maiores e traços) e isotópicas $(\mathrm{Sr}, \mathrm{Nd}$ e $\mathrm{Pb}$ ) das rochas graníticas estudadas.

Foram efetuadas pela metodologia U-Pb (convencional) 42 análises de diferentes frações magnéticas de zircão extraídas de 10 amostras das rochas graníticas estudadas. Estas análises foram realizadas no Centro de Pesquisas Geocronológicas da Universidade de São Paulo (CPGeoUSP), cujos procedimentos químicos e isotópicos adotados encontram-se detalhados em Basei et al. (1995) e Prazeres Filho (2000). A seleção dos cristais de zircão para as análises geocronológicas buscou sempre os cristais mais bem formados, transparentes, limpos e de mesma tipologia.

\section{Batólito G ranítico Cunhaporanga (BCP)}

O BCP apresenta três unidades graníticas principais denominadas informalmente como Unidade Granítica Ribeirão Butiá (URB), Unidade Granítica Santa Rita (URS) e Unidade Granítica Piraí do Sul (UPS). Os estudos petrográficos revelaram que estas unidades do BCP são constituídas predominantemente por monzogranitos e subordinadamente granodioritos porfiríticos a inequigranulares, isótropos e por vezes protomiloníticos (Figuras 2 e 3 ).

A Unidade Granítica Ribeirão Butiá (URB) é predominante no BCP (Figura 2) e está constituída por hornblendabiotita monzogranitos a granodioritos cinzentos, de granulação média, porfiríticos e isótropos, com megacristais (até $4 \mathrm{~cm}$ ) de K-feldspato euédricos e, ocasionalmente megacristais de plagioclásio. Os principais minerais acessórios são zircão, titanita, allanita, apatita e opacos. São comuns nas rochas desta unidade a ocorrência de enclaves dioríticos ovalados e microgranulares.

Foram analisadas frações magnéticas de zircão de um hornblenda biotita granodiorito porfirítico (amostra HP-02) e um hornblenda biotita monzogranito porfirítico (amostra HP-03). Nas duas amostras analisadas as frações de zircão são discordantes em diagrama Concórdia (Figuras 4A e B).

Na amostra HP-02 as frações de zircão M(-4a), M(-5) e $\mathrm{M}(-4 \mathrm{~b})$ indicam tendência de herança com idades ${ }^{207} \mathrm{~Pb} /{ }^{206} \mathrm{~Pb}$ de $746 \pm 14 \mathrm{Ma}, 660 \pm 6 \mathrm{Ma}$ e $648 \pm 6 \mathrm{Ma}$, respectivamente (Tabela 1 e Figura 4A). As frações NM(-5) e M(-4) são os pontos analíticos de maior concordância e apresentam idades ${ }^{207} \mathrm{~Pb} /{ }^{206} \mathrm{~Pb}$ de $625 \pm 10 \mathrm{Ma}$ e $624 \pm 3 \mathrm{Ma}$. Ressalta-se a semelhança da idade K-Ar (anfibólio) de $616 \pm 21$ Ma obtida nesta mesma amostra por Prazeres Filho (2000). Com relação ao resultado U-Pb da amostra HP-03, as frações de zircão 


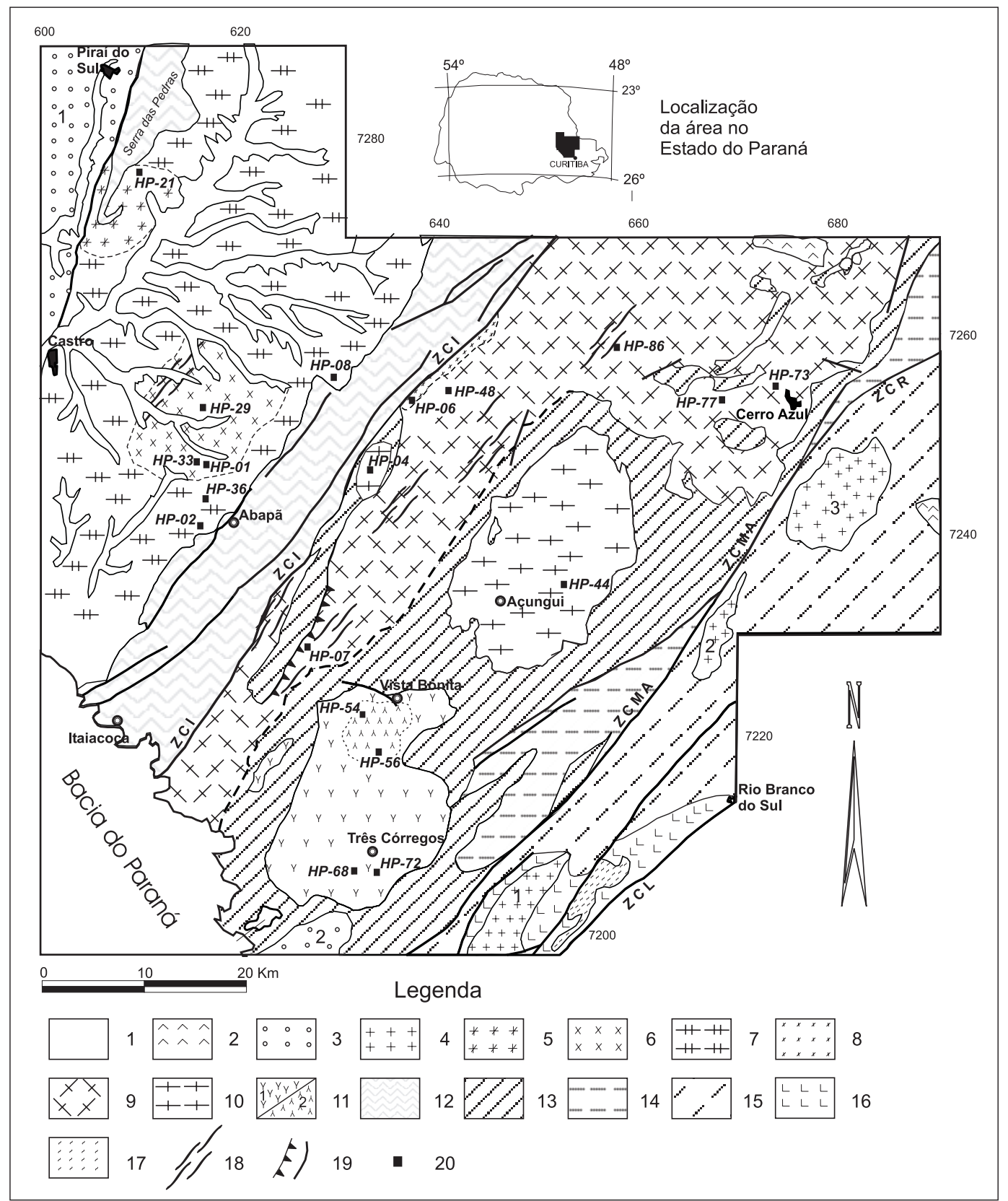

Figura 2. Mapa geológico dos Batólitos graníticos Cunhaporanga e Três Córregos no Estado do Paraná (Mod. CPRM, 1977; Biondi et al. 1983; Reis Neto, 1994; G uimarães, 2000; Prazeres Filho, 2000).

1. Cobertura Fanerozóica (BP, Bacia do Paraná); 2. Maciços alcalinos mesozóicos; 3. Bacias eopaleozóicas: 1 - Grupo Castro, 2 - Formação Camarinha; 4. Granitóides alcalinos neoproterozóicos (570 - 560 Ma): 1 - Cerne, 2 - Piedade, 3 - Morro Grande; Batólito Granítico Cunhaporanga: 5. Unidade Piraí do Sul, biotita monzogranitos; 6. Unidade Santa Rita, biotita monzogranitos porfiríticos; 7. Unidade Ribeirão Butiá, hornblenda biotita monzogranitos a granodioritos porfiríticos; Batólito Granítico Três Córregos: 8. Unidade Paina, hornblenda biotita tonalitos pouco deformados; 9. Unidade Arrieiros, hornblenda biotita monzogranitos a granodioritos porfiríticos; 10. Unidade São Sebastião, hornblenda biotita quartzo monzonitos porfiríticos; 11. Unidade Conceição: 1 - Facies Arroio Taquaral, hornblenda biotita sieno a monzogranitos; 2 - Facies Vista Bonita, hornblenda biotita monzogranitos; Supergrupo Açungui: 12. Grupo Itaiacoca (metacalcários, metarenitos, metatraquitos, filitos e mica xistos); 13. Formação Água Clara (metamargas, xistos e metabásicas); 14. Subgrupo Lageado (Metassiltitos, metaritmitos, conglomerados, quartzitos); 15. Formação Votuverava (filitos, mica xistos, metabásicas); 16. Formação Betara (xistos, metabásicas, metacherts); 17. Núcleo granítico paleoproterozóico; 18. Rochas graníticas miloníticas a protomiloníticas; 19. Zonas de Cisalhamento (ZC): ZCL - Lancinha, ZCMA - Morro Agudo, ZCR - Ribeira, ZCI - Itapirapuã; 20. Localização das amostras selecionadas para as análises geocronológicas e isotópicas U-Pb, $\mathrm{Nd}, \mathrm{Sr}$ e Pb. 
Figura 3. Diagrama Q AP (Streckeisen, 1976) mostrando a composição modal dos litotipos graníticos estudados.

Batólito Cunhaporanga (BCP): UPS - Unidade Piraí do Sul; USR - Unidade Santa Rita; URB - Unidade Ribeirão do Butiá. Batólito Três Córregos (BTC): UPN - Unidade Paina; UAR - Unidade Arrieiros; USS - Unidade São Sebastião; UCN - Unidade Conceição.

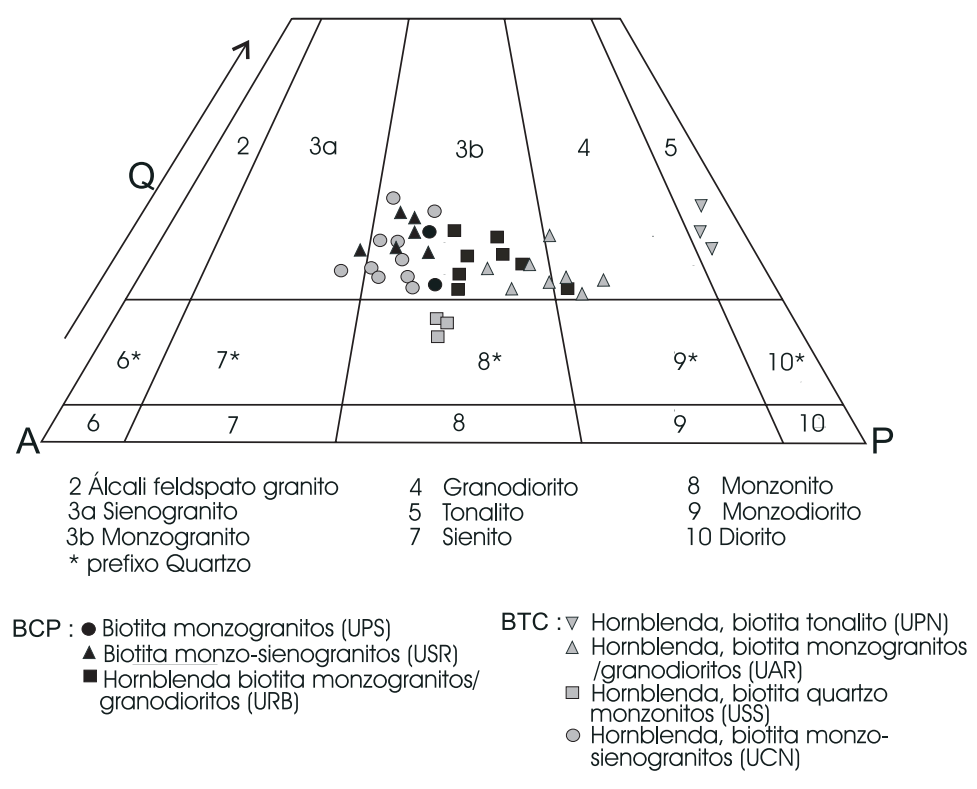

M(-5), M(-4a) e M(-3) apresentam um bom alinhamento e indicam uma idade do intercepto superior de $625 \pm 4 \mathrm{Ma}$ (MSWD $=2,9$ ), porém com idade de intercepto inferior negativo, o que indica graus de discordância e perda de $\mathrm{Pb}$ distintas para essas frações. A fração M(-4b) apresenta idade ${ }^{207} \mathrm{~Pb} /{ }^{206} \mathrm{~Pb}$ de $624 \pm 3 \mathrm{Ma}$ (Tabela 1 e Figura 4B). Os dados U-Pb das amostras HP-02 e HP-03 apresentados permitem inferir que as rochas graníticas da URB se formaram num período entre 625 a $624 \mathrm{Ma}$.

A Unidade Granítica Santa Rita (USR), ocorre na porção central do BCP (Figura 2) e sua extensão geográfica foi baseada em Guimarães (2000). Constitui-se principalmente por biotita monzogranitos porfiríticos róseos a avermelhados isótropos e ocasionalmente deformados. Apresentam megacristais de K-feldspato euédricos (com até $2 \mathrm{~cm}$ ), distribuídos em uma matriz equigranular média a fina. Os principais minerais acessórios destas rochas são apatita, zircão e titanita. Foram analisadas 5 frações magnéticas de zircão de um biotita monzogranito porfirítico (HP-01) com abrasão somente da fração M(-4) até o arredondamento dos cristais (Tabela 1 e Figura 4C).

As idades U-Pb obtidas em todas as frações de zircão analisadas são discordantes (Tabela 1 e Figura 4C). Para o cálculo da idade desta rocha não foi considerado o alinhamento das frações $\mathrm{M}(-1), \mathrm{M}(-2)$ e $\mathrm{M}(0)$, pois estas apresentam forte perda de $\mathrm{Pb}$ e precário alinhamento, com erro da ordem de $\pm 120 \mathrm{Ma}$. Com exceção da fração $\mathrm{M}(0)$, as idades ${ }^{207} \mathrm{~Pb} /{ }^{206} \mathrm{~Pb}$ das demais frações indicam heranças (Tabela 1 ). $\mathrm{O}$ alto erro analítico da idade ${ }^{207} \mathrm{~Pb} /{ }^{206} \mathrm{~Pb}$ de $588 \pm$ '70' $\mathrm{Ma}$ não permite a precisão da idade de formação desta rocha.
Desta forma é delimitado o período, com base nas idades U-Pb das outras rochas graníticas do BCP, de 620 a 590 Ma, como o mais provável da formação dos monzogranitos desta unidade.

A Unidade Granítica Piraí do Sul (UPS), ocorre na extremidade NW do BCP (Figura 2) e é intrusiva nos domínios da Unidade Ribeirão Butiá. Constitui-se por biotita monzogranitos cinzentos, leucocráticos, equi a inequigranulares, de granulação média a fina, isótropos e apresentam textura xenomórfica. Os principais minerais acessórios são titanita, apatita, allanita e zircão.

Foram analisadas 3 frações magnéticas de zircão de um biotita monzogranito (amostra HP-21). As idades U-Pb obtidas em todas as frações analisadas são discordantes, com indicação de herança sugerida pelas idades ${ }^{207} \mathrm{~Pb} /{ }^{206} \mathrm{~Pb}$ de $715 \pm 16 \mathrm{Ma}$ e $647 \pm 8 \mathrm{Ma}$, respectivamente das frações M(-3) e M(-5). A fração mais concordante, M(-4), apresenta idade ${ }^{207} \mathrm{~Pb} /{ }^{206} \mathrm{~Pb}$ de $601 \pm 7 \mathrm{Ma}$, interpretada como indicativa da idade máxima da formação dos monzogranitos desta unidade granítica (Tabela 1 e Figura 4D).

\section{Batólito Granítico Três Córregos (BTC)}

As principais unidades graníticas definidas no BTC são: Unidade Granítica Arrieiros (UAR), Unidade Granítica São Sebastião (USS), Unidade Granítica Conceição (UCN) e Unidade Granítica Paina (UPN). Os estudos petrográficos revelaram que estas unidades são constituídas por granodioritos, monzogranitos e quartzo monzonitos 
Tabela 1. Resultados analíticos U-Pb em zircão das rochas graníticas do Batólito Cunhaporanga e do Batólito Três Córregos. aa - abradada; na - não abradada.

\begin{tabular}{|c|c|c|c|c|c|c|c|c|c|c|c|c|c|}
\hline $\begin{array}{c}\text { Fração } \\
\text { Magnética }\end{array}$ & $\begin{array}{l}\text { Peso } \\
\text { (mg) }\end{array}$ & $\begin{array}{c} \\
\text { (ppm) }\end{array}$ & $\begin{array}{c}\mathrm{Pb} \\
(\mathrm{ppm})\end{array}$ & $\begin{array}{l}\mathrm{Pb}^{206} / \\
\mathrm{Pb}^{204} \\
\end{array}$ & $\begin{array}{c}\mathrm{Pb}^{207} \mathrm{I} \\
\mathrm{U}^{235} \\
\end{array}$ & $\begin{array}{c}\text { Erro\% } \\
2(\sigma) \\
\end{array}$ & $\begin{array}{c}\mathrm{Pb}^{206} \mathrm{I} \\
\mathrm{U}^{238} \\
\end{array}$ & $\begin{array}{c}\text { Erro\% } \\
2(\sigma) \\
\end{array}$ & $\begin{array}{l}\mathrm{Pb}^{206} / \\
\mathrm{Pb}^{207} \\
\end{array}$ & $\begin{array}{c}\text { Erro\% } \\
2(\sigma) \\
\end{array}$ & $\begin{array}{c}\mathrm{Pb}^{206} \mathrm{I} \\
\mathrm{U}^{238} \\
\end{array}$ & $\begin{array}{c}\mathrm{Pb}^{207} \mathrm{I} \\
\mathrm{U}^{235} \\
\end{array}$ & $\begin{array}{l}\mathrm{Pb}^{207} \mathrm{I} \\
\mathrm{Pb}^{206}\end{array}$ \\
\hline \multicolumn{14}{|c|}{ BATÓLITO CUNHAPORANGA } \\
\hline \multicolumn{14}{|c|}{ Amostra HP-21, Biotita Monzogranito - Unidade Piraí do Sul } \\
\hline$M(-3)$ na & 0,087 & 215 & 23 & 1067 & 0,817925 & 1,56 & 0,093875 & 1,35 & 0,063192 & 0,76 & 578 & 607 & $715 \pm 16$ \\
\hline$M(-4)$ na & 0,101 & 270 & 30 & 975 & 0,756132 & 0,98 & 0,091496 & 0,93 & 0,059937 & 0,31 & 564 & 572 & $601 \pm 7$ \\
\hline$M(-5)$ na & 0,079 & 242 & 27 & 995 & 0,81157 & 1,03 & 0,096156 & 0,93 & 0,061214 & 0,36 & 592 & 603 & $647 \pm 8$ \\
\hline \multicolumn{14}{|c|}{ Amostra HP-01, Biotita Monzogranito - Unidade Santa Rita } \\
\hline$M(0)$ na & 0,00179 & 584 & 68 & 83 & 0,621493 & 6,6 & 0,075634 & 5,67 & 0,059596 & 3,22 & 470 & 491 & $589 \pm 70$ \\
\hline$M(-1)$ na & 0,075 & 1359 & 86 & 432 & 0,48166 & 1,93 & 0,057688 & 1,89 & 0,060555 & 0,38 & 361 & 399 & $623 \pm 8$ \\
\hline$M(-2)$ na & 0,08 & 1712 & 98 & 348 & 0,430587 & 1,05 & 0,05025 & 1,02 & 0,062149 & 0,23 & 316 & 364 & $680 \pm 5$ \\
\hline$M(-3)$ na & 0,082 & 673 & 59 & 386 & 0,691619 & 1,1 & 0,078448 & 1,03 & 0,063942 & 0,38 & 486 & 534 & $740 \pm 8$ \\
\hline$M(-4)$ aа & 0,134 & 405 & 41 & 514 & 0,998482 & 0,85 & 0,090649 & 0,8 & 0,079887 & 0,19 & 559 & 703 & $1194 \pm 4$ \\
\hline \multicolumn{14}{|c|}{ Amostra HP-02, Hornblenda Biotita Granodiorito -Unidade Ribeirão Butia } \\
\hline$M(-4 a)$ aa & 0,059 & 221 & 25 & 500 & 0,864031 & 1,22 & 0,097714 & 1,01 & 0,064132 & 0,65 & 601 & 632 & $746 \pm 14$ \\
\hline$M(-4 b)$ na & 0,05 & 200 & 20 & 2308 & 0,798388 & 0,96 & 0,094535 & 0,91 & 0,061252 & 0,3 & 582 & 596 & $648 \pm 6$ \\
\hline$M(-4 c)$ na & 0,046 & 264 & 29 & 1036 & 0,798639 & 0,52 & 0,095671 & 0,51 & 0,060543 & 0,1 & 589 & 596 & $623 \pm 3$ \\
\hline$M(-5)$ na & 0,054 & 221 & 23 & 2262 & 0,809936 & 0,96 & 0,095385 & 0,91 & 0,061584 & 0,27 & 587 & 602 & $660 \pm 6$ \\
\hline$N M(-5)$ na & 0,095 & 176 & 19 & 772 & 0,804206 & 1,29 & 0,096269 & 1,1 & 0,060587 & 0,67 & 592 & 599 & $625 \pm 10$ \\
\hline \multicolumn{14}{|c|}{ Amostra HP-03, Hornblenda Biotita Monzogranito -Unidade Ribeirão Butia } \\
\hline$M(-3)$ na & 0,044 & 241 & 24 & 1216 & 0,759589 & 0,52 & 0,089998 & 0,5 & 0,061213 & 0,14 & 556 & 574 & $647 \pm 3$ \\
\hline$M(-4 a)$ na & 0,045 & 229 & 24 & 1184 & 0,790965 & 0,51 & 0,094165 & 0,49 & 0,060921 & 0,11 & 580 & 592 & $636 \pm 3$ \\
\hline$M(-4 b)$ na & 0,022 & 288 & 30 & 1412 & 0,796322 & 0,66 & 0,095346 & 0,64 & 0,060573 & 0,15 & 587 & 595 & $624 \pm 3$ \\
\hline$M(-5)$ na & 0,04 & 229 & 25 & 1755 & 0,803756 & 0,51 & 0,095695 & 0,5 & 0,060916 & 0,07 & 589 & 599 & $636 \pm 2$ \\
\hline \multicolumn{14}{|c|}{ BATÓLITO GRANIITICO TRÊS CÓRREGOS } \\
\hline \multicolumn{14}{|c|}{ Amostra HP-06, Hornblenda Biotita Tonalito - Unidade Paina } \\
\hline$M(-3)$ na & 0,118 & 230 & 23 & 2764 & 0,792773 & 0,83 & 0,094861 & 0,79 & 0,060612 & 0,24 & 584 & 593 & $626 \pm 5$ \\
\hline$M(-3)$ aa & 0,113 & 265 & 31 & 545 & 1,06921 & 1,01 & 0,104251 & 0,97 & 0,074384 & 0,27 & 639 & 738 & $1052 \pm 6$ \\
\hline$M(-4)$ aa & 0,09 & 565 & 64 & 2790 & 0,886469 & 1,2 & 0,099428 & 1,18 & 0,064663 & 0,12 & 611 & 644 & $763 \pm 4$ \\
\hline$M(-5)$ na & 0,085 & 637 & 65 & 3446 & 0,844535 & 1,11 & 0,097903 & 1,09 & 0,062563 & 0,23 & 602 & 621 & $693 \pm 5$ \\
\hline$N M(-5)$ na & 0,091 & 368 & 37 & 2574 & 0,829518 & 1,21 & 0,098636 & 1,2 & 0,060994 & 0,21 & 606 & 613 & $639 \pm 5$ \\
\hline \multicolumn{14}{|c|}{ Amostra HP-07, Hornblenda Biotita Granodiorito protomilonítico - Unidade Arrieiros } \\
\hline$M(-5)$ na & 0,103 & 260 & 25 & 2006 & 0,767599 & 0,9 & 0,091574 & 0,87 & 0,060794 & 0,2 & 565 & 578 & $632 \pm 4$ \\
\hline$N M(-5)$ na & 0,093 & 231 & 24 & 1952 & 0,796659 & 0,72 & 0,094959 & 0,69 & 0,060846 & 0,21 & 585 & 595 & $634 \pm 5$ \\
\hline$M(-4 a)$ na & 0,25 & 157 & 17 & 734 & 0,788357 & 0,76 & 0,093757 & 0,58 & 0,060984 & 0,45 & 578 & 590 & $639 \pm 10$ \\
\hline$M(-4 b)$ aa & 0,283 & 171 & 18 & 1650 & 0,833368 & 0,91 & 0,097103 & 0,9 & 0,062245 & 0,1 & 597 & 615 & $683 \pm 2$ \\
\hline \multicolumn{14}{|c|}{ Amostra HP-73, Hornblenda Biotita Granodiorito - Unidade Arrieiros } \\
\hline$M(-5)$ na & 0,089 & 110 & 12 & 639 & 0,82294 & 0,92 & 0,098153 & 0,89 & 0,060808 & 0,22 & 604 & 610 & $632 \pm 5$ \\
\hline$M(-6)$ na & 0,086 & 80 & 8 & 688 & 0,833536 & 0,89 & 0,099493 & 0,85 & 0,060466 & 0,28 & 606 & 609 & $620 \pm 5$ \\
\hline$N M(-6)$ & 0,092 & 109 & 13 & 307 & 0,82201 & 1,2 & 0,098597 & 1,18 & 0,060762 & 0,26 & 611 & 615 & $630 \pm 6$ \\
\hline \multicolumn{14}{|c|}{ Amostra HP-04, Hornblenda Biotita Qz Monzonito - Unidade São Sebastião } \\
\hline $\mathrm{M}(-5)$ aa & 0,108 & 412 & 45 & 3536 & 1,17074 & 1,68 & 0,105414 & 1,62 & 0,080549 & 0,45 & 646 & 789 & $1211 \pm 9$ \\
\hline$M(-4)$ na & 0,14 & 418 & 43 & 1516 & 0,947278 & 0,97 & 0,100142 & 0,91 & 0,068606 & 0,31 & 615 & 677 & $887 \pm 6$ \\
\hline$M(-3)$ na & 0,15 & 332 & 34 & 1475 & 0,897761 & 1,14 & 0,099721 & 0,91 & 0,065294 & 0,62 & 613 & 650 & $784 \pm 13$ \\
\hline \multicolumn{14}{|c|}{ Amostra HP-44, Hornblenda Biotita Qz Monzonito - Unidade São Sebastião } \\
\hline$N M(-5)$ na & 0,091 & 306 & 40 & 873 & 0,813845 & 0,82 & 0,098191 & 0,64 & 0,060113 & 0,47 & 604 & 605 & $608 \pm 10$ \\
\hline$M(-5)$ na & 0,098 & 210 & 25 & 1541 & 0,845489 & 0,7 & 0,099141 & 0,64 & 0,061852 & 0,25 & 609 & 622 & $669 \pm 6$ \\
\hline$M(-4)$ na & 0,095 & 285 & 34 & 1319 & 0,861338 & 0,64 & 0,099751 & 0,6 & 0,062626 & 0,18 & 613 & 631 & $696 \pm 4$ \\
\hline \multicolumn{14}{|c|}{ Amostra HP-68, Hornblenda Biotita Monzogranito - Unidade Conceição, Fácies Arroio Taquaral } \\
\hline$N M(-4 a)$ aa & 0,04 & 138 & 18 & 425 & 1,27829 & 1,89 & 0,109033 & 1,88 & 0,085029 & 0,23 & 667 & 836 & $1316 \pm 5$ \\
\hline$N M(-4 b)$ na & 0,094 & 389 & 41 & 595 & 0,829381 & 1,82 & 0,08905 & 1,76 & 0,067549 & 0,46 & 550 & 613 & $855 \pm 10$ \\
\hline$M(-4)$ na & 0,15 & 389 & 42 & 744 & 0,930205 & 2,06 & 0,094431 & 1,78 & 0,071443 & 1,01 & 582 & 668 & $970 \pm 21$ \\
\hline$M(-3)$ na & 0,1 & 291 & 33 & 1134 & 1,126101 & 0,96 & 0,100899 & 0,8 & 0,080945 & 0,5 & 620 & 766 & $1220 \pm 10$ \\
\hline \multicolumn{14}{|c|}{ Amostra HP-56, Hornblenda Biotita Monzogranito - Unidade Conceição, Fácies Vista Bonita } \\
\hline$M(-1)$ na & 0,066 & 249 & 23 & 525 & 0,797091 & 0,91 & 0,089403 & 0,87 & 0,064662 & 0,25 & 552 & 595 & $763 \pm 5$ \\
\hline$M(-2)$ na & 0,079 & 280 & 31 & 776 & 1,18909 & 0,79 & 0,10309 & 0,78 & 0,083656 & 0,14 & 632 & 795 & $1285 \pm 3$ \\
\hline$M(-3)$ na & 0,082 & 241 & 18 & 1021 & 0,671711 & 0,94 & 0,076927 & 0,91 & 0,063329 & 0,21 & 478 & 522 & $719 \pm 5$ \\
\hline
\end{tabular}



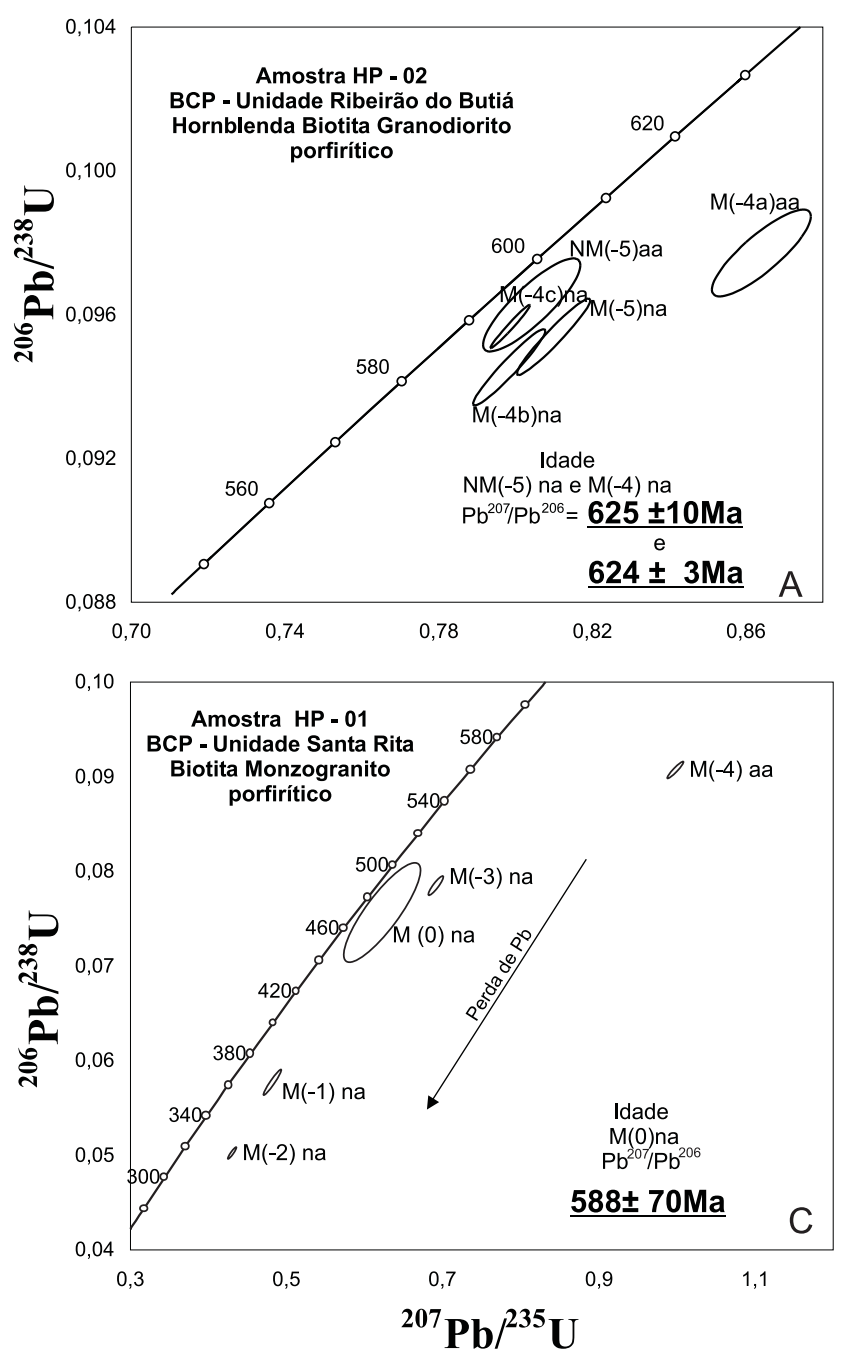
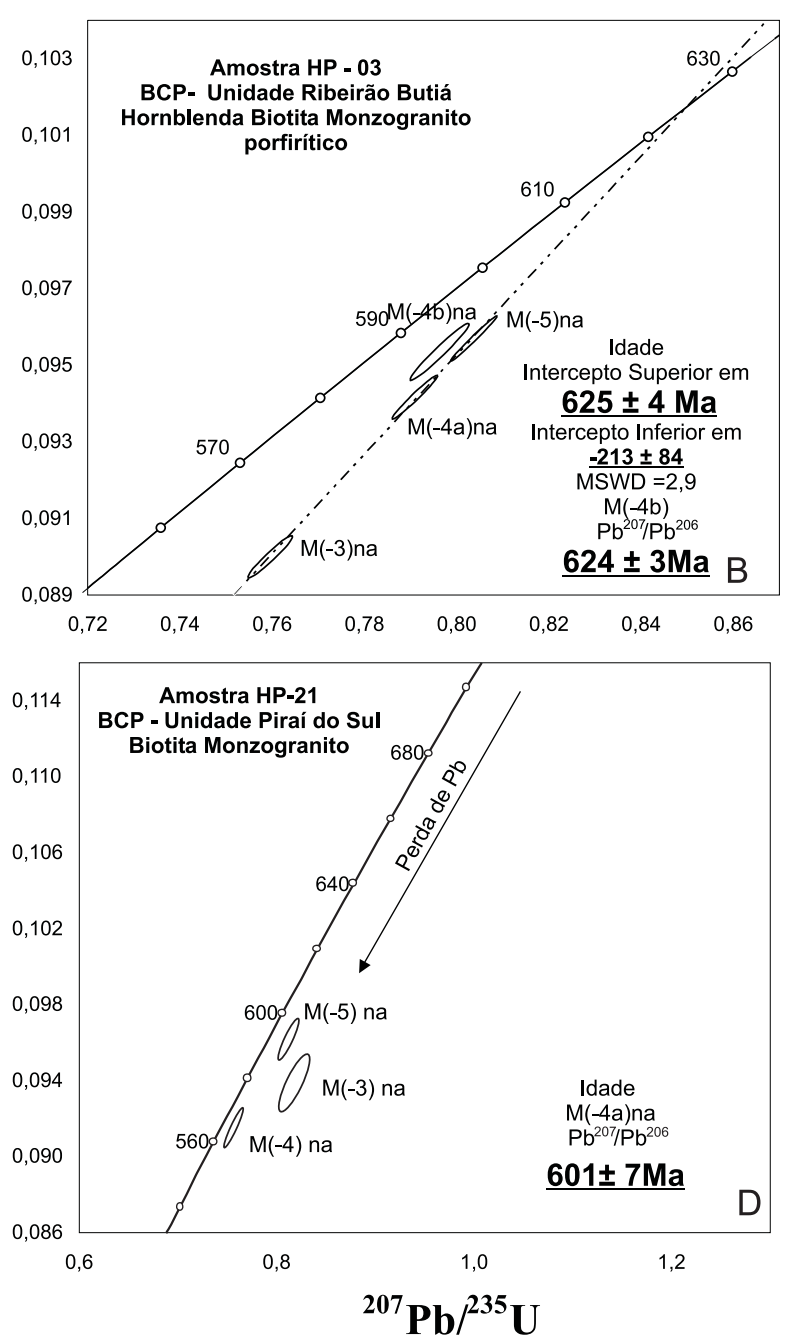

Figura 4. Diagramas Concórdia U- $\mathrm{Pb}\left({ }^{207} \mathrm{~Pb} /{ }^{235} \mathrm{U} \times{ }^{206} \mathrm{~Pb} /{ }^{238} \mathrm{U}\right)$ das frações de zircão analisadas das rochas graníticas do Batólito Cunhaporanga (aa - frações abradadas e na - não abradadas).

porfiríticos, deformados ou não e subordinadamente tonalitos e sienogranitos (Figuras 2 e 3 ).

A Unidade Granítica Arrieiros (UAR), ocupa toda a porção NW e N do BTC (Figura 2) e é constituída por hornblenda biotita monzogranitos a granodioritos porfiríticos de cor cinza, deformados (protomilonitos) ou não, com freqüentes megacristais (até $6 \mathrm{~cm}$ ) de K-feldspato e raros de plagioclásio.

O contato geológico da porção oeste da UAR com o Grupo Itaiacoca é marcado pela Zona de Cisalhamento Itapirapuã. Com a Formação Água Clara os contatos são em parte intrusivos e em parte tectônicos (Figura 2).
Feições sugestivas de interação magmática entre rochas granodioríticas e rochas dioríticas ocorrem na porção norte da UAR (Prazeres Filho, 2000). As características estruturais e texturais observadas nestes dois tipos litológicos sugerem mistura de dois diferentes magmas, um máfico (diorito) e um félsico (granodiorito).

Foram analisadas 4 frações magnéticas de zircão de um hornblenda biotita granodiorito protomilonítico (amostra HP-07) e de um hornblenda biotita granodiorito porfirítico isótropo (amostra HP-73), conforme indicado na Figura 2. Os dados analíticos U-Pb destas rochas são apresentados na Tabela 1 e Figuras 5A e B. 

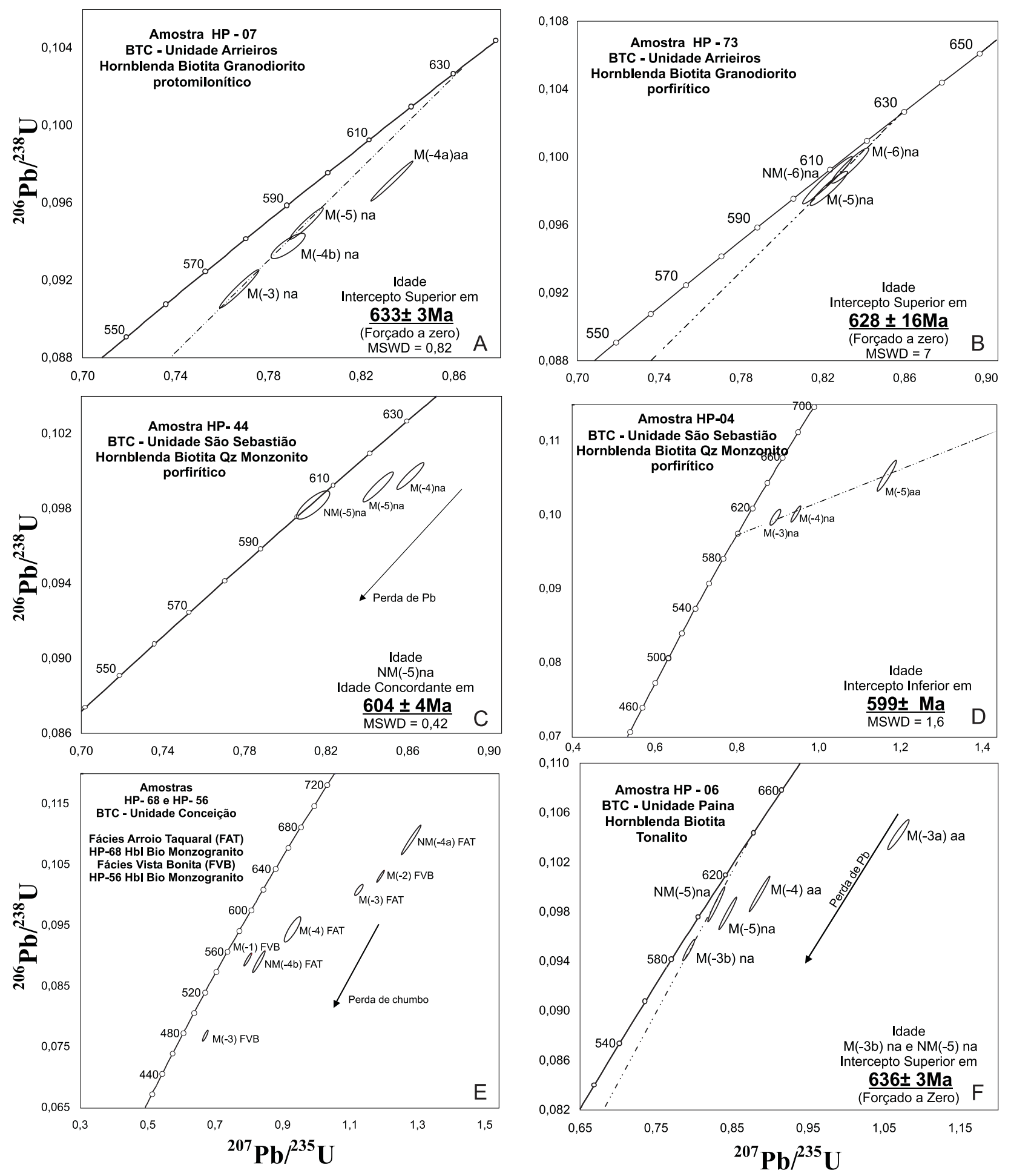

Figura 5. Diagramas Concórdia U- $\mathrm{Pb}\left({ }^{207} \mathrm{~Pb} /{ }^{235} \mathrm{U} \times{ }^{206} \mathrm{~Pb} /{ }^{238} \mathrm{U}\right)$ das frações de zircão analisadas das rochas graníticas do Batólito Três Córregos (aa - frações abradadas e na - não abradadas). 
Com exceção dos cristais de zircão abradados da fração $\mathrm{M}(-4 \mathrm{a})$, os resultados analíticos do granodiorito protomilonítico (amostra HP-07) apresentam um bom alinhamento e indicam uma idade do intercepto superior de $633 \pm 3 \mathrm{Ma}(\mathrm{MSWD}=0,82)$ (Figura 5A). No granodiorito isótropo (amostra HP-73) o alinhamento das frações de zircão analisadas indica a idade do intercepto superior de $628 \pm 16$ $\mathrm{Ma}(\mathrm{MSWD}=4,6)$, similar à idade da amostra do granodiorito protomilonítico (Figura 5B). Pelo exposto é possível inferir que as rochas graníticas da UAR se formaram no período entre $633 \mathrm{Ma}$ a $630 \mathrm{Ma}$.

A Unidade Granítica São Sebastião (USS), ocorre na porção central do BTC, intrusiva nas rochas metavulcanosedimentares da Formação Água Clara, configurando um corpo batolítico, com dimensões de aproximadamente $250 \mathrm{~km}^{2}$. A USS também ocorre na forma de stock granítico intrusivo nos granitóides da UAR (Figura 2). A USS é constituída por hornblenda biotita quartzo-monzonitos com titanita, cinzentos, porfiríticos, de granulação grossa e isótropos. Apresentam megacristais $(3 \mathrm{a} 5 \mathrm{~cm}$ ) euédricos de K-feldspato poiquilíticos, ocorrendo ainda megacristais com até $12 \mathrm{~cm}$. Os principais minerais acessórios são allanita, zircão, apatita e opacos.

Foram analisadas 3 frações de zircão de um hornblenda biotita quartzo monzonito porfirítico (amostra HP-44) intrusivo na Formação Água Clara e 3 frações de zircão, sendo uma abradada (M-5) de um hornblenda biotita quartzo monzonito porfirítico (amostra HP-04) intrusivo na UAR.

Os zircões das frações M(-4) e M(-5) da amostra HP-44 são discordantes, indicando herança com idades ${ }^{207} \mathrm{~Pb} /{ }^{206} \mathrm{~Pb}$ de $695 \pm 4$ Ma e $669 \pm 6$ Ma respectivamente (Tabela 1). Entretanto, os cristais de zircão da fração NM(-5) são concordantes com a curva concórdia e indicam a idade de $604 \pm 4 \mathrm{Ma}$, interpretada como a idade de formação desta rocha (Figura 5C).

Os cristais de zircão das frações M(-3), M(-4) e M(-5) da amostra HP-04 são muito discordantes e com forte indicação de herança, apresentando idades aparentes ${ }^{207} \mathrm{~Pb} /{ }^{206} \mathrm{~Pb}$ de $784 \pm 13 \mathrm{Ma}, 887 \pm 6 \mathrm{Ma}$, e $1210 \pm 9 \mathrm{Ma}$, respectivamente (Tabela 1). A idade do intercepto inferior de $599 \pm 7 \mathrm{Ma}$ (Figura 5D) é interpretada como a idade de formação desta rocha. Esta idade de intercepto inferior é corroborada pela idade K-Ar em anfibólio de 597士12 Ma (Prazeres Filho, 2000), bem como pela idade U-Pb em zircão da amostra HP-44 (604 Ma), integrante da mesma unidade granítica. Com base nestes resultados é sugerido que a idade de formação das rochas graníticas da USS está entre 604 e 600 Ma.

A Unidade Granítica Conceição (UCN) ocorre ao sul da USS, na forma de um corpo batolítico, de aproximadamente $260 \mathrm{~km}^{2}$, e encontra-se alojada em meio às rochas metavulcano-sedimentares da Formação Água Clara (Figura 2).

Na UCN são reconhecidas duas facies graníticas: uma predominante, denominada de Facies Arroio Taquaral e, outra de menor expressão em área, denominada de Facies Vista Bonita. Esta última, identificada e definida como Granito Vista Bonita por Santos \& Felipe (1980).

A Facies Arroio Taquaral é constituída por hornblenda biotita monzogranitos e raros sienogranitos isótropos, inequigranulares, de coloração avermelhada e granulação média. Os principais minerais acessórios são titanita, zircão, apatita e allanita. A Facies Vista Bonita é constituída por hornblenda biotita monzogranitos hololeucocráticos de coloração rósea claro, equi a inequigranulares e isótropos.

Foram analisados um total de sete frações de zircão de duas amostras, um hornblenda biotita monzogranito (amostra HP-68) da Facies Arroio Taquaral e um hornblenda biotita monzogranito (amostra HP-56) da Facies Vista Bonita (Tabela 1 e Figura 5E). Os resultados obtidos nas frações de zircão dessas duas amostras foram tratados em conjunto em diagrama Concórdia e são inconclusivos, devido a grande dispersão das frações de zircão e pela presença de herança em seus cristais (Figura 5E).

A Unidade Granítica Paina (UPN) ocorre na extremidade NW do BTC (Figura 2) em contato tectônico com os metassedimentos do Grupo Itaiacoca definido pela Zona de Cisalhamento Itapirapuã. A UPN é constituída principalmente por hornblenda biotita tonalitos pouco deformados, de coloração cinza escuro, granulação média e inequigranulares. Os principais minerais acessórios destas rochas são: zircão, titanita, apatita e allanita.

Foram analisadas 5 frações de zircão (amostra HP-06) com abrasão somente das frações M(-3a) e M(-4). Os resultados obtidos (Tabela 1 e Figura 5F) mostram idades discordantes com forte indicação de heranças nas frações M(-3a), $\mathrm{M}(-4)$ e $\mathrm{M}(-5)$ com idades ${ }^{207} \mathrm{~Pb} /{ }^{206} \mathrm{~Pb}$ de $1051 \pm 6 \mathrm{Ma}$, $763 \pm 4$ Ma e $693 \pm 5$ Ma respectivamente. Por outro lado, os cristais das frações $\mathrm{NM}(-5)$ e M(-3b), também discordantes, mostram idades ${ }^{207} \mathrm{~Pb} /{ }^{206} \mathrm{~Pb}$ de $639 \pm 5 \mathrm{Ma}$ e $625 \pm 5 \mathrm{Ma}$. O alinhamento dessas frações resulta numa idade de $636 \pm 3 \mathrm{Ma}$ (Figura 5F), interpretada como a melhor estimativa da idade de cristalização das rochas desta unidade.

Pelo exposto, a aplicação da metodologia U-Pb (convencional) para o estabelecimento da cronologia dos diferentes litotipos graníticos do BCP e do BTC mostrou-se problemática em rochas que possuem cristais de zircão com histórias de heranças isotópicas. As idades U-Pb nestes cristais com heranças podem não possuir significado geológico, uma vez que as perdas de $\mathrm{Pb}$ radiogênico e/ou a mistura de cristais restíticos de zircão de diferentes fontes 
com cristais neoformados, podem causar idades mais jovens, mais antigas ou híbridas, sem significado geológico (Rogers et al., 1989; Roddick \& Bevier, 1995; Pidgeon et al., 1996; Mezger \& Krogstad, 1997). Nestes casos é necessário o uso de outras metodologias geocronológicas (e. g. K-Ar e Ar-Ar) para verificar se as idades de intercepto inferior apresentam ou não significado geológico.

Apesar da complexidade demonstrada pelo sistema U-Pb sugere-se para o BCP o intervalo entre 625 a $590 \mathrm{Ma}$ para a formação de seus constituintes graníticos. Este período mostrou-se mais jovem do que as idades isocrônicas Rb-Sr (RT) de $746 \pm 45$ Ma para os 'Gnaisses Piraí do Sul' (UPS, amostra HP-21) (Reis Neto, 1994).

No BTC, as idades U-Pb em zircão indicam um período muito próximo ao sugerido para o BCP, entre 636 e $600 \mathrm{Ma}$ para a formação de suas unidades graníticas. A formação dos tonalitos da UPN (amostra HP-06) e dos granodioritos da UAR (amostras HP-07 e HP-73) ocorreu entre 636 a 630 Ma. Reis Neto (1994) obteve idades isocrônicas Rb-Sr (RT) de $658 \pm 49$ Ma para os 'Gnaisses Paina' (UPN). Gimenez Filho et al. (2000), pela metodologia U-Pb em zircão, obtiveram idades ${ }^{207} \mathrm{~Pb} /{ }^{206} \mathrm{~Pb}$ de $608 \pm 5 \mathrm{Ma}$ para os quartzo monzodioritos sódicos (augen gnaisse) que ocorrem a noroeste de Apiaí - SP sendo, portanto, mais jovens que os tonalitos sódicos da UPN (amostra HP-06).

Com base nos resultados U-Pb obtidos em zircão dos quartzo-monzonitos da USS (amostras HP-04 e HP-44) a idade da formação das rochas desta unidade está entre 604 e 599 Ma. Para litotipos semelhantes na região ao norte de Apiaí - SP (Granito Saival), Gimenez Filho et al. (op.cit) obtiveram a idade $\mathrm{U}-\mathrm{Pb}$ em zircão de $605 \pm 2 \mathrm{Ma}$.

\section{LITOQUÍMICA E GEOQUÍMICA ISOTÓ PICA}

As análises litoquímicas das rochas graníticas estudadas do BCP e BTC foram efetuadas no Activation Laboratories (Canadá), onde os óxidos foram dosados pelo método ICP e os elementos traços pelo método ICP-MS. As análises isotópicas de $\mathrm{Nd}$ e $\mathrm{Sr}$ em rocha total e $\mathrm{Pb}$ em Kfeldspato foram efetuadas no CPGeo-USP e os procedimentos laboratoriais para a aquisição dos dados isotópicos de $\mathrm{Nd}, \mathrm{Sr}$ e Pb, encontram-se detalhados em Sato et al. (1995) e Prazeres Filho (2000).

Os resultados das análises litoquímicas e isotópicas (Tabelas 2A e B e Tabela 3 dos litotipos graníticos do BCP e BTC foram tratados em conjunto na maioria dos diagramas, com o objetivo de observar as diferentes assinaturas litoquímicas e isotópicas e apresentar inferências petrogenéticas e geotectônicas.
Em geral os litotipos graníticos do BCP são cálcio-alcalinos de alto $\mathrm{K}$ e metaluminosos a fracamente peraluminosos. Os litotipos graníticos do BTC são cálcio-alcalinos de médio e alto $\mathrm{K}$ e predominantemente metaluminosos (Figuras 6A, B e C). O contraste litoquímico mais evidente entre o BCP e o BTC está no comportamento dos elementos $\mathrm{Na}_{2} \mathrm{O}$ e $\mathrm{K}_{2} \mathrm{O}$. As rochas graníticas do BCP são em geral mais potássicas e as do BTC são relativamente mais sódicas (Figura 6D).

Como as rochas graníticas estudadas do BCP e do BTC apresentam variação de $\mathrm{SiO}_{2}$ entre 60 e $75 \%$ (Tabelas $2 \mathrm{~A}$ e $\mathrm{B}), \mathrm{o} \mathrm{SiO}$ é utilizado como o melhor índice de discriminação, análise e comparação dos dados litoquímicos em diagramas de variação $\mathrm{SiO}_{2}$ x principais óxidos e traços (Figura 7). Na porção investigada do $\mathrm{BCP}$, as rochas graníticas são de composições predominantemente félsicas com $\mathrm{SiO}_{2}$ entre 65 e $73 \%$, enquanto que na porção investigada do BTC as rochas graníticas são de composições intermediárias a félsicas com $\mathrm{SiO}_{2}$ entre 60 e $75 \%$. As principais diferenças no conteúdo dos elementos maiores e traços entre as rochas das unidades graníticas do BCP e BTC são evidenciadas pelos teores mais elevados em $\mathrm{K}_{2} \mathrm{O}, \mathrm{TiO}_{2}, \mathrm{MgO}, \mathrm{Rb}$ e Ga do BCP em relação ao BTC, e dos teores mais elevados em $\mathrm{Na}_{2} \mathrm{O}, \mathrm{Al}_{2} \mathrm{O}_{3}, \mathrm{CaO}, \mathrm{Fe}_{2} \mathrm{O}_{3}, \mathrm{Zr}, \mathrm{Nb}, \mathrm{Ba}$ e $\mathrm{Sr}$ do BTC em relação ao BCP (Figura 7 - Tabela 2).

No BCP diferenças litoquímicas são também observadas entre suas unidades graníticas. A USR $\left(\mathrm{SiO}_{2}=73\right.$ a 74\%) e a UPS $\left(\mathrm{SiO}_{2}=70 \%\right)$ são caracterizadas por rochas fracamente peraluminosas (Figura 6B), com teores altos de $\mathrm{Rb}$ e baixos de $\mathrm{Sr}$, ambas bem contrastantes com a URB (Tabela 2A e Figura 7). A USR apresenta teores mais baixos em Y e $\mathrm{Nb}$ em relação a UPS que apresenta altos teores nestes elementos. Estes dados sugerem que a USR é constituída por rochas graníticas sin-colisionais, sugestivas da tipologia granítica S. Já a UPS é constituída por rochas graníticas tardi a pós-colisionais, sugestivas da tipologia granítica A. As rochas graníticas da URB $\left(\mathrm{SiO}_{2}=65\right.$ a $\left.66 \%\right)$ apresentam altos teores de $\mathrm{Sr}$ e Ba e baixos de $\mathrm{Rb}, \mathrm{Ga}, \mathrm{Y}$ e $\mathrm{Nb}$, características litoquímicas de rochas graníticas cálcio-alcalinas, sugestivas da tipologia granítica I, formadas em ambiente de arcos magmáticos (Tabela $2 \mathrm{~A} \mathrm{e}$ Figuras 6, 7 e 8). Com base nestas informações é sugerida no BCP a existência de produtos graníticos distintos e não cogenéticos.

No BTC diferenças litoquímicas entre suas unidades graníticas são observadas na maioria dos diagramas de $\mathrm{SiO}_{2} \times$ elementos maiores e traços (Figura 6). A USS $\left(\mathrm{SiO}_{2}=62-67 \%\right)$ comparada com a UAR $\left(\mathrm{SiO}_{2}=62-68 \%\right)$, possui teores mais elevados em $\mathrm{TiO}_{2}, \mathrm{~K}_{2} \mathrm{O}$ e Rb e mais baixos em $\mathrm{Na}_{2} \mathrm{O}, \mathrm{Al}_{2} \mathrm{O}_{3}$ e $\mathrm{Zr}$. A única amostra da UPN $\left(\mathrm{SiO}_{2}=59 \%\right)$, distingue-se das rochas menos diferenciadas 


\begin{tabular}{cc|ccc|ccccc}
\hline \multicolumn{2}{c}{ Unidades UPS } & \multicolumn{3}{c}{ USR } & & & \multicolumn{3}{c}{ URB } \\
Amostras & HP-21 & HP-33 & HP-29 & HP-01 & HP-36 & HP-03 & HP-08 & HP-09 & HP-02 \\
\hline $\mathrm{SiO}_{2}$ & 71,06 & 73,12 & 73,13 & 73,6 & 64,75 & 65,6 & 65,92 & 66,03 & 66,18 \\
$\mathrm{Na}_{2} \mathrm{O}$ & 3,24 & 3,88 & 4,17 & 4,18 & 3,55 & 3,62 & 3,77 & 3,58 & 3,64 \\
$\mathrm{~K}_{2} \mathrm{O}$ & 4,85 & 4,99 & 5,24 & 5,05 & 4,43 & 4,39 & 4,13 & 4,6 & 4,3 \\
$\mathrm{CaO}$ & 1,71 & 0,86 & 1,36 & 1,21 & 3,57 & 2,84 & 2,83 & 3,17 & 3,22 \\
$\mathrm{Al}_{2} \mathrm{O}_{3}$ & 14,49 & 14,04 & 15,14 & 14,8 & 15,16 & 14,66 & 14,92 & 15,19 & 14,87 \\
$\mathrm{Fe}_{2} \mathrm{O}_{3}$ & 2,78 & 1,09 & 0,98 & 0,97 & 4,51 & 3,94 & 4 & 4,1 & 3,87 \\
$\mathrm{MgO}_{\mathrm{TiO}}$ & 0,85 & 0,14 & 0,28 & 0,21 & 2,14 & 1,96 & 1,68 & 1,77 & 1,92 \\
$\mathrm{Sr}$ & 0,42 & 0,19 & 0,17 & 0,15 & 0,91 & 0,76 & 0,86 & 0,81 & 0,76 \\
$\mathrm{Rb}$ & 405 & 316 & 349 & 407 & 1059 & 880 & 818 & 938 & 892 \\
$\mathrm{Ga}$ & 212 & 239 & 216 & 248 & 114 & 136 & 131 & 144 & 137 \\
$\mathrm{Ba}$ & 940 & 746 & 663 & 750 & 1879 & 1565 & 1222 & 1642 & 1411 \\
$\mathrm{Zr}$ & 190 & 133 & 122 & 103 & 262 & 221 & 229 & 228 & 220 \\
$\mathrm{Nb}$ & 14 & 4,6 & 3,6 & 5,9 & 12 & 10 & 11 & 11 & 10 \\
$\mathrm{Y}$ & 45 & 14 & 3 & 5,9 & 14 & 26 & 12 & 13 & 26 \\
\hline
\end{tabular}

Tabela 2A. Análises litoquímicas das rochas do Batólito Cunhaporanga (BCP). Monzogranito: UPS - Unidade Piraí do Sul; Monzogranitos porfiríticos: USR - Unidade Santa Rita; Monzogranitos a granodioritos porfiríticos: URB - Unidade Ribeirão Butiá.

Tabela 2B. Análises litoquímicas das rochas do Batólito Três Córregos (BTC).

\begin{tabular}{|c|c|c|c|c|c|c|c|c|c|c|c|c|c|c|}
\hline \multirow{2}{*}{$\begin{array}{l}\text { Unidades } \\
\text { Amostras }\end{array}$} & \multirow{2}{*}{$\begin{array}{c}\text { UPN } \\
\text { HP-06 }\end{array}$} & \multicolumn{7}{|c|}{ UAR } & \multicolumn{2}{|c|}{ USS } & \multicolumn{4}{|c|}{ UCN } \\
\hline & & HP-77 & HP-07 & HP -83 & HP-73 & HP-86 & HP -48 & HP-88 & HP-44 & HP-04 & HP-72 & HP-68 & HP-56 & HP-54 \\
\hline $\mathrm{SiO}_{2}$ & 59,28 & 61,93 & 63,46 & 63,98 & 64,82 & 64,99 & 65,91 & 67,75 & 62,41 & 66,56 & 70,65 & 71,53 & 73,79 & 74,48 \\
\hline $\mathrm{Na}_{2} \mathrm{O}$ & 5,83 & 4,32 & 4,55 & 4,04 & 4,33 & 4,44 & 4,68 & 4,74 & 3,69 & 4,79 & 4,19 & 4,01 & 4,59 & 4,68 \\
\hline $\mathrm{CaO}$ & 4,27 & 4,05 & 3,24 & 3,66 & 3,63 & 3,69 & 3,66 & 3,19 & 4,45 & 2,74 & 1,5 & 1,65 & 1,19 & 1,55 \\
\hline $\mathrm{Al}_{2} \mathrm{O}_{3}$ & 18,28 & 16,13 & 16,15 & 15,84 & 15,63 & 15,69 & 16 & 15,81 & 14,45 & 16,06 & 14,13 & 14,08 & 14,5 & 14,15 \\
\hline $\mathrm{Fe}_{2} \mathrm{O}_{3}$ & 4,68 & 6,01 & 4,32 & 5,55 & 4,75 & 5,58 & 4,2 & 3,84 & 6,22 & 2,97 & 2,14 & 2,21 & 1,13 & 1,55 \\
\hline $\mathrm{MgO}$ & 2,09 & 2,58 & 1,8 & 1,97 & 2,02 & 1,77 & 1,57 & 1,15 & 2,8 & 0,98 & 0,7 & 0,7 & 0,23 & 0,34 \\
\hline $\mathrm{TiO}_{2}$ & 0,76 & 0,92 & 0,68 & 0,73 & 0,68 & 0,62 & 0,64 & 0,48 & 1 & 0,45 & 0,36 & 0,41 & 0,17 & 0,18 \\
\hline $\mathrm{Sr}$ & 1249 & 1330 & 1063 & 1280 & 1230 & 949 & 932 & 861 & 1050 & 1161 & 664 & 668 & 773 & 860 \\
\hline $\mathrm{Rb}$ & 49 & 67 & 72 & 72 & 75 & 70 & 65 & 73 & 91 & 111 & 179 & 158 & 120 & 63 \\
\hline $\mathrm{Ga}$ & 29 & 25 & 24 & 22 & 23 & 23 & 24 & 23 & 23 & 26 & 25 & 24 & 24 & 23 \\
\hline $\mathrm{Ba}$ & 759 & 2070 & 1536 & 2260 & 2000 & 1440 & 1340 & 1100 & 1920 & 1464 & 1590 & 1560 & 1350 & 1150 \\
\hline $\mathrm{Zr}$ & 274 & 300 & 265 & 299 & 274 & 245 & 264 & 219 & 335 & 254 & 216 & 204 & 136 & 180 \\
\hline $\mathrm{Nb}$ & 13 & 13 & 12 & 11 & 10 & 11 & 12 & 12 & 17 & 13 & 7,4 & 7,8 & 6,6 & 5,1 \\
\hline $\mathrm{Y}$ & 16 & 19 & 14 & 16 & 14 & 15 & 17 & 12 & 24 & 28 & 23 & 7 & 6,2 & 41 \\
\hline
\end{tabular}

Tonalito: UPN - Unidade Paina; Monzogranitos a granodioritos porfiríticos: UAR - Unidade Arrieiros; Qz monzonitos porfiríticos: USS - Unidade São Sebastião; Sieno a monzogranitos: UCN - Unidade Conceição. 
Tabela 3. Dados isotópicos Sm-Nd, Rb-Sr e Pb-Pb em rocha total dos litotipos graníticos estudados dos Batólitos Cunhaporanga (BCP) e Três Córregos (BTC). Números em parênteses são os erros dos dois últimos dígitos das razões isotópicas.

\begin{tabular}{|c|c|c|c|c|c|c|c|c|c|c|c|c|c|c|c|}
\hline Amostra & $\begin{array}{c}\mathrm{Sm} \\
(\mathrm{ppm})\end{array}$ & $\begin{array}{c}\mathrm{Nd} \\
(\mathrm{ppm})\end{array}$ & $\begin{array}{l}{ }^{147} \mathrm{Sm} / \\
{ }^{144} \mathrm{Nd}\end{array}$ & $\begin{array}{l}{ }^{143} \mathrm{Nd} / \\
{ }^{144} \mathrm{Nd}\end{array}$ & $\begin{array}{c}\mathrm{Tdm} \\
\mathbf{G a}\end{array}$ & $\varepsilon_{\mathrm{Nd}} 0$ & $\varepsilon_{\mathrm{Nd}}^{(\mathrm{t})}$ & $\begin{array}{c}\mathrm{Rb} \\
(\mathrm{ppm})\end{array}$ & $\begin{array}{c}\mathrm{Sr} \\
(\mathrm{ppm})\end{array}$ & $\begin{array}{l}{ }^{87} \mathrm{Rb} / \\
{ }^{86} \mathrm{Sr}\end{array}$ & $\begin{array}{l}{ }^{87} \mathrm{Sr} / \\
{ }^{86} \mathrm{Sr}\end{array}$ & $\begin{array}{l}{ }^{87} \mathrm{Sr} / \\
{ }^{86} \mathrm{Sr} \mathrm{i}\end{array}$ & $\begin{array}{l}{ }^{206} \mathrm{~Pb} / \\
{ }^{204} \mathrm{~Pb}\end{array}$ & $\begin{array}{l}{ }^{207} \mathrm{~Pb} / \\
{ }^{204} \mathrm{~Pb}\end{array}$ & $\begin{array}{l}{ }^{208} \mathrm{~Pb} / \\
{ }^{204} \mathrm{~Pb}\end{array}$ \\
\hline \multicolumn{16}{|c|}{ BATÓLITO GRANÍTICO CUNHAPORANGA } \\
\hline \multicolumn{16}{|c|}{ Biotita Monzogranito inequigranular - Unidade Piraí do Sul (UPS) } \\
\hline \multicolumn{16}{|c|}{ Bitotita Monzogranito porfiritico - Unidade Santa Rita (USR) } \\
\hline HP-01 & 3,5 & 18,6 & 0,1138 & $0,511614(09)$ & 2.18 & $-19,98$ & $-13,63$ & 248 & 407 & 1,767 & $0,729753(19)$ & 0,71463 & $17,39(38)$ & $15,57(37)$ & $37,602(38)$ \\
\hline HP-29 & 1,68 & 11,7 & 0,0868 & $0,511520(13)$ & 1.82 & $-21,81$ & $-13,4$ & 216 & 349 & 1,796 & $0,732443(23)$ & 0,71708 & & & \\
\hline HP-33 & 4,63 & 27 & 0,1037 & $0,511678(11)$ & 1.89 & $-18,73$ & $-11,61$ & & & & & & & & \\
\hline \multicolumn{16}{|c|}{ Hornblenda Biotita Monzogranito a granodiorito- Unidade Ribeirão Butiá (URB) } \\
\hline HP-02 & 6,77 & 43,5 & 0,0941 & $0,511558(10)$ & 1.89 & $-21,07$ & $-13,22$ & 137 & 892 & 0,445 & $0,714723(64)$ & 0,71092 & $17,328(57)$ & $15,551(59)$ & $37,503(61)$ \\
\hline HP-08 & 7,73 & 49,9 & 0,0937 & $0,511660(10)$ & 1.75 & $-19,08$ & $-11,19$ & 131 & 818 & 0,464 & $0,714349(33)$ & 0,71038 & & & \\
\hline HP-36 & 8,79 & 53,5 & 0,0994 & $0,511576(10)$ & 1.95 & $-20,72$ & $-13,27$ & 114 & 1059 & 0,312 & $0,713725(20)$ & 0,71106 & & & \\
\hline \multicolumn{16}{|c|}{ BATÓLITO GRANÍTICO TRÊS CÓRREGOS } \\
\hline \multicolumn{16}{|c|}{ Hornblenda Biotita Monzogranito a granodiorito - Unidade Arrieiros (UAR) } \\
\hline HP-07 & 7,96 & 48,5 & 0,0992 & $0,511320(15)$ & 2.30 & $-25,71$ & $-18,25$ & 72 & 1063 & 0,196 & $0,71103(20)$ & 0,70935 & $16,415(45)$ & $15,33(46)$ & $36,669(47)$ \\
\hline HP-48 & 8,42 & 49,7 & 0,1024 & $0,511314(14)$ & 2.37 & $-25,83$ & $-18,61$ & 65 & 932 & 0,203 & $0,710796(22)$ & 0,70906 & & & \\
\hline HP-77 & 12,1 & 76,4 & 0,0958 & $0,511332(14)$ & 2.21 & $-25,48$ & $-17,75$ & 67 & 1330 & 0,145 & $0,711265(20)$ & 0,71002 & & & \\
\hline HP-86 & 7,91 & 48,2 & 0,0992 & $0,511335(10)$ & 2.28 & $-25,42$ & $-17,96$ & 70 & 949 & 0,213 & $0,710833(107)$ & 0,70901 & & & \\
\hline \multicolumn{16}{|c|}{ Hornblenda Biotita Qz Monzonito - Unidade São Sebastião } \\
\hline HP-04 & 9,35 & 59,4 & 0,0952 & $0,511337(09)$ & 2.19 & $-25,38$ & $-17,61$ & 111 & 1161 & 0,277 & $0,712072(26)$ & 0,7097 & & & \\
\hline HP-44 & 11 & 63,1 & 0,1054 & $0,511341(11)$ & 2.40 & $-25,3$ & $-18,31$ & 91 & 1050 & 0,252 & $0,713249(36)$ & 0,7111 & $16,42(07)$ & $15,419(67)$ & $36,877(72)$ \\
\hline \multicolumn{16}{|c|}{ Hornblenda Biotita Monzo a sienogranito - Unidade Conceição } \\
\hline HP-54 & 5,43 & 28,4 & 0,1156 & $0,511334(13)$ & 2.28 & $-25,44$ & $-19,23$ & 63 & 860 & 0,212 & $0,711319(21)$ & 0,70951 & & & \\
\hline HP-56 & 3,93 & 22 & 0,108 & $0,511333(12)$ & 2.47 & $-25,46$ & $-18,67$ & 120 & 773 & 0,45 & $0,714556(26)$ & 0,71071 & & & \\
\hline HP-68 & 5,13 & 34,9 & 0,0889 & $0,511240(10)$ & 2.20 & $-27,27$ & $-19,02$ & 158 & 668 & 0,686 & $0,71725(17)$ & 0,71138 & $16,098(03)$ & $15,377(30)$ & $36,573(31)$ \\
\hline HP-72 & 5,32 & 33 & 0,0975 & $0,511269(18)$ & 2.33 & $-26,71$ & $-19,11$ & 179 & 664 & 0,781 & $0,71851(18)$ & 0,71183 & & & \\
\hline
\end{tabular}



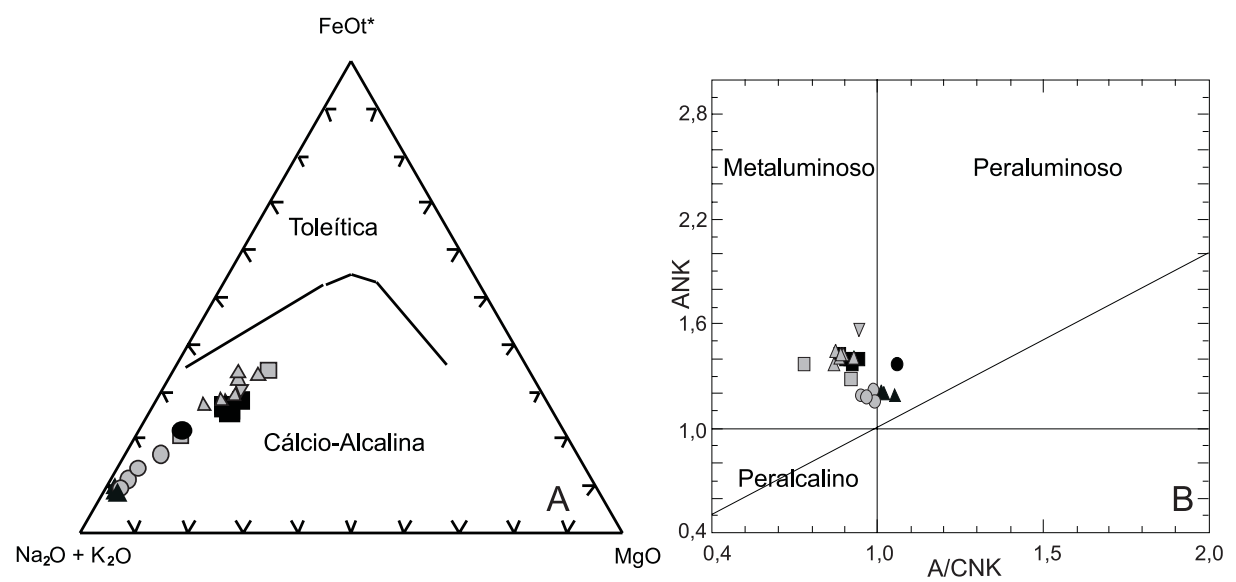

Figura 6. Diagramas discriminantes aplicados às rochas graníticas do BCP e do BTC.

A - Diagrama AFM (Irvine \& Baragar, 1971); B - Índice de SHAND, segundo diagrama de Maniar \& Picolli (1989); C - Diagrama de variação $\mathrm{SiO}_{2} \times \mathrm{K}_{2} \mathrm{O}$ com os campos das rochas das séries ígneas cálcio alcalinas de alto $\mathrm{K}$, médio $\mathrm{K}$, baixo $\mathrm{K}$ e shoshoníticas (Rickwood et al. 1989); D - Diagrama de variação $\mathrm{Na}_{2} \mathrm{O} \times \mathrm{K}_{2} \mathrm{O}$ com os campos das séries ígneas de alto $\mathrm{K}$, potássicas e sódicas (Middlemost, 1975). Legenda dos símbolos: idem Figura 3.

da UAR, pelos teores mais baixos em $\mathrm{Ba}$ e $\mathrm{Rb}$ e mais altos em $\mathrm{Na}_{2} \mathrm{O}, \mathrm{Al}_{2} \mathrm{O}_{3}$ e em $\mathrm{Ga}$. A UCN $\left(\mathrm{SiO}_{2}=70-73 \%\right)$ em diagramas de $\mathrm{SiO}_{2}$ x Rb, Sr e $\mathrm{Nb}$ apresenta comportamento distinto em relação às demais unidades graníticas do BTC (Tabela 2B e Figura 7).

As diferenças nos teores de $\mathrm{Sr}, \mathrm{Ba}, \mathrm{Ga}, \mathrm{Rb}, \mathrm{Y}$ e $\mathrm{Nb}$ das unidades graníticas UPN e UAR em relação às demais unidades do BTC, permitem sugerir que são rochas graníticas, cálcio-alcalinas, sugestivas da tipologia I, de arcos magmáticos. A USS e UCN, por outro lado, são compatíveis com rochas graníticas cálcio-alcalinas, sugestivas da tipologia I tardi a pós-colisionais (Tabela 2B e Figuras 6, 7 e 8).

Independentemente do local de alojamento e da idade de formação das rochas graníticas das diferentes unidades do BCP e BTC, suas assinaturas litoquímicas permitem sugerir a existência de distintos produtos graníticos em cada batólito.

Os resultados isotópicos de $\mathrm{Nd}, \mathrm{Sr}$ e $\mathrm{Pb}$ das rochas do BCP e BTC são apresentados na Tabela 3 e nas Figuras 9A, B, C e D. As idades modelo (TDM) que sugerem o período em que os protólitos das rochas graníticas foram diferenciados do manto e incorporados à crosta continental, são paleoproterozóicas entre 2,1 a 1,8 Ga para o BCP e entre 2,4 a 2,2 Ga para o BTC. O padrão de evolução dos isótopos de $\mathrm{Nd}$ (Figura 9A) e de $\varepsilon_{\mathrm{Nd}}{ }^{(\mathrm{t})} \mathrm{X}{ }^{87} \mathrm{Sr} /{ }^{86} \mathrm{Sr}(\mathrm{i})$ mostram claramente assinaturas de $\mathrm{Nd}$ e $\mathrm{Sr}$ distintas para as rochas do BCP e do BTC, sugerindo fontes distintas para a geração das rochas graníticas de cada um destes batólitos. Nos isótopos de $\mathrm{Nd}$, observam-se valores distintos e altamente negativos de $\varepsilon_{\mathrm{Nd}}{ }^{(\mathrm{t})}$ entre $-13 \mathrm{e}-11$ para o BCP e entre $-19 \mathrm{e}-17$ para o BTC (Figuras 9A e B). Estes valores indicam um tempo relativamente longo de residência crustal das fontes que participaram na geração do magmatismo do BCP e BTC.

As razões iniciais de ${ }^{87} \mathrm{Sr} /{ }^{86} \mathrm{Sr}(\mathrm{i})$ para as rochas do BCP estão entre 0,709 e 0,711 para a URB e UPS e entre 0,714 e 0,717 para a USR. Para as rochas do BTC as razões ${ }^{87} \mathrm{Sr} /{ }^{86} \mathrm{Sr}$ (i) estão entre 0,709 a 0,710 para a UAR, entre 0,712 a 0,713 para USS e entre 0,711 a 0,718 para a UCN (Tabela 3 ). As razões ${ }^{87} \mathrm{Sr} /{ }^{86} \mathrm{Sr}$ (i) com valores maiores que 0,707 são indicativas da contribuição de fontes crustais para a formação das rochas do BCP e BTC. Os valores dessas razões quando confrontados com os valores de $\varepsilon_{\mathrm{Nd}}{ }^{(\mathrm{t})}$, sugerem a participação de distintas fontes infracrustais para a formação do BCP e do BTC, com a exceção da USR do BCP, su- 

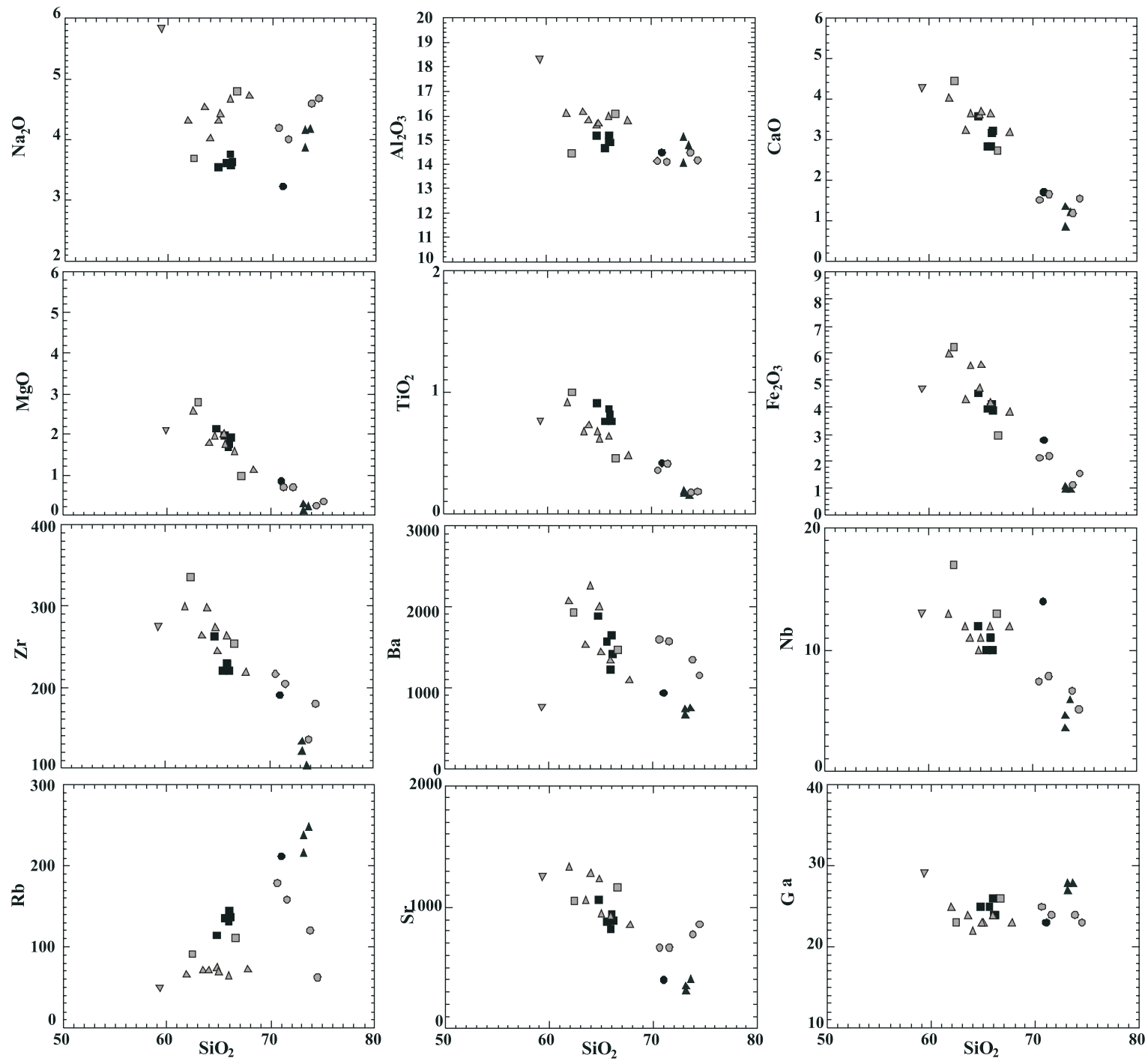

Figura 7. Diagramas de variação $\mathrm{SiO}_{2}$ x principais óxidos e traços. Legenda dos símbolos: idem Figura 3.

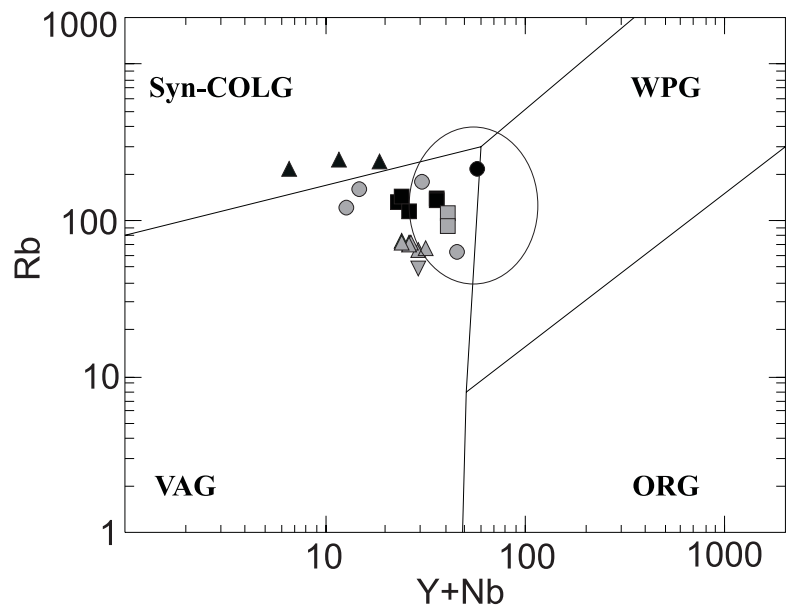

Figura 8. Diagrama $\mathrm{Rb} \times(\mathrm{Y}+\mathrm{Nb})$ de discriminação tectônica de rochas graníticas (Pearce et al., 1984) aplicado para o BCP, BTC.

Syn-COLG - Granitos sin-colisionais; WPG - Granitos Intraplacas; VAG - Granitos de Arco Vulcânico; ORG - Granitos de cadeia oceânica. $O$ círculo indica o campo das rochas graníticas pós-colisionais (Pearce, 1996). Legenda dos símbolos: idem Figura 3. 

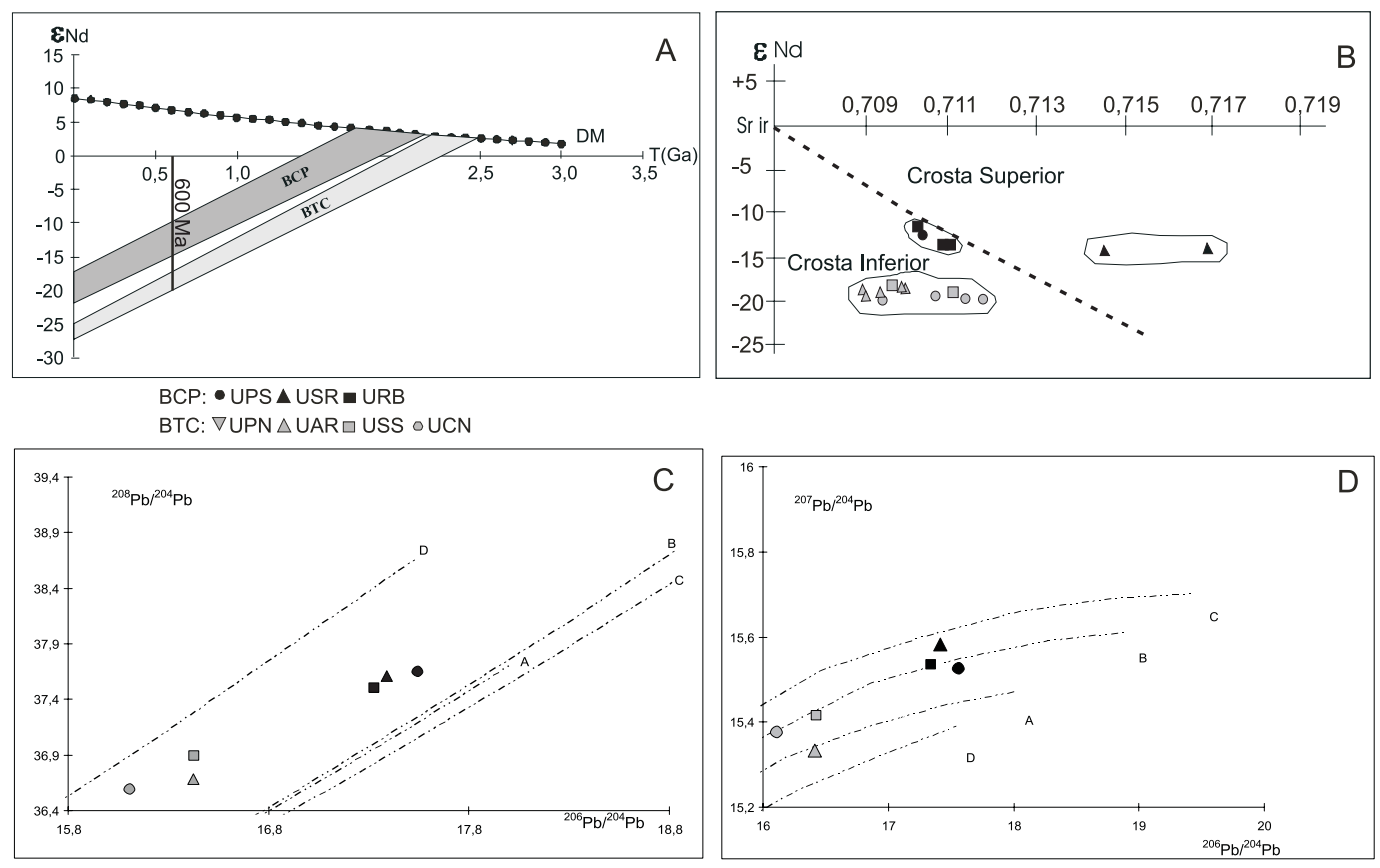

Figura 9. Diagramas isotópicos $\mathrm{Nd}, \mathrm{Sr}$ e $\mathrm{Pb}$ aplicados às rochas do $\mathrm{BCP}$ e BTC.

A - Diagrama de evolução de $\varepsilon_{\mathrm{Nd}} \times$ tempo $(\mathrm{Ga})$; B - Diagrama de ${ }^{87} \mathrm{Sr} /{ }^{86} \mathrm{Sr}$ inicial $\times \boldsymbol{\varepsilon}_{\mathrm{Nd}}$ para $\mathrm{t}=600 \mathrm{Ma}$ (campos da crosta superior e crosta inferior segundo DePaolo \& Wasserburg, 1979); C e D - Diagramas do modelo de plumbotectônica (Zartman \& Doe, 1981) - curvas dos reservatórios isotópicos: C. crosta superior, B. orogene, A. manto, D. crosta inferior. Legenda dos símbolos: idem Figura 3.

gestiva da participação de fontes sedimentares supracrustais na sua formação (Figura 9B).

Uma alternativa para explicar as diferenças isotópicas de Nd entre o BCP e BTC, seria a formação das rochas graníticas de ambos os batólitos por refusão de rochas gnáissicas e granulíticas máficas paleoproterozóicas em ambiente de margem continental ativa, porém com maior contribuição de uma componente mantélica na geração do BCP.

Os dados dos isótopos de $\mathrm{Pb}$ (K-feldspato) das rochas graníticas do BCP e BTC (Tabela 3) foram tratados em diagramas de evolução ${ }^{207} \mathrm{~Pb} /{ }^{204} \mathrm{~Pb} \mathrm{x}{ }^{206} \mathrm{~Pb} /{ }^{204} \mathrm{~Pb}$ e ${ }^{206} \mathrm{~Pb} /{ }^{204} \mathrm{~Pb} \mathrm{x}$ ${ }^{208} \mathrm{~Pb} /{ }^{204} \mathrm{~Pb}$ (Plumbotectônica - Zartman \& Doe, 1981) e mostram assinaturas isotópicas de $\mathrm{Pb}$ distintas entre o $\mathrm{BCP}$ e o BTC e entre suas unidades graníticas (Figuras 9C e D). A análise conjunta destes dados sugere a mistura de diferentes fontes infracrustais com fontes mantélicas para a geração das rochas graníticas dos dois batólitos. Comportamento distinto é observado nos isótopos de $\mathrm{Pb}$ da USR, onde fontes supracrustais são indicadas (Figura 9D).
Os dados litoquímicos e isotópicos ( $\mathrm{Nd}, \mathrm{Sr}$ e $\mathrm{Pb}$ ) apresentados sugerem que as rochas graníticas do BCP e BTC foram originadas a partir de maior ou menor grau de mistura entre fontes mantélicas e fontes máficas infracrustais paleoproterozóicas. Mistura com fontes supracrustais são mais indicadas às rochas da USR.

O comportamento isotópico do $\mathrm{Nd}$ nas rochas do BCP e do BTC é distinto do observado no magmatismo granítico do arco Mara Rosa da Faixa Brasília - GO (Pimentel \& Fuck, 1992; Pimentel et al., 1996) e do Bloco São Gabriel na região de Cerro Mantiqueiras - RS (Leite et al., 1998), onde são registrados eventos de acresção de material juvenil Neoproterozóico com os valores do $\varepsilon_{\mathrm{Nd}}^{\left({ }^{(t)}\right.}$ positivos a pouco negativos e, idades modelo neoproterozóicas. Por outro lado, as rochas do BCP e BTC apresentam valores negativos similares às rochas graníticas do Cinturão Granítico de Florianópolis - SC (Basei, 2000) e do Cinturão Granítico PiênMandirituba - PR/SC (Harara, 2001), onde há claros sinais de contribuições crustais. 


\section{CONCLUSÕES}

Os estudos petrográficos e litoquímicos e a integração de trabalhos anteriores permitiram separar tipos graníticos distintos nas porções estudadas do BCP e do BTC, definidos como unidades graníticas informais.

As análises litoquímicas mostram claramente a existência de produtos graníticos distintos, um caracteristicamente mais potássico a NW (BCP) e outro mais sódico a $\mathrm{SE}$ (BTC). A distinção entre os produtos graníticos, internamente no BCP e no BTC, é melhor observada no conteúdo e no comportamento da maioria dos elementos traços.

A partir dos dados petrológicos foi possível caracterizar a URB do BCP e a UAR e UPN do BTC como unidades graníticas compostas por granodioritos e monzogranitos e raros tonalitos da tipologia granítica I, metaluminosos, cálcio-alcalinos de alto $\mathrm{K}$, formados em ambiente de margem continental ativa e sendo as principais rochas plutônicas componentes de um arco magmático. As idades $\mathrm{U}-\mathrm{Pb}$ em zircão destas rochas indicam que o período da construção deste arco magmático ocorreu provavelmente entre 630 a $605 \mathrm{Ma}$, ou seja, dentro de um intervalo de aproximadamente $25 \mathrm{Ma}$.

A UPS do BCP e a USS e UCN do BTC são constituídas respectivamente por monzogranitos e quartzo-monzonitos e monzo a sienogranitos fracamente peraluminosos (aluminosos) e metaluminosos, de alto K, formadas em ambiente sin- a tardi-colisonal. A USR do BCP é constituída por monzogranitos, fracamente peraluminosos, cálcio-alcalinos de alto $\mathrm{K}$, formados em ambiente sin- a tardi-colisional. As idades U-Pb em zircão delimitam o período de formação das rochas destas unidades graníticas sin- a tardi-colisionais entre 620 a $590 \mathrm{Ma}$. O período compreendido entre 590 a 560 Ma está associado ao magmatismo pós-colisional a anorogênico da porção sul do Cinturão Ribeira, representado pelos stocks graníticos Capão Bonito, Sguário, Córreas, Morro Grande, Carambeí, Joaquim Murtinho, Cerne, Passa Três etc.

Os dados isotópicos de $\mathrm{Sr}$, $\mathrm{Nd}$ e $\mathrm{Pb}$ sugerem para a formação dos componentes graníticos do BCP e do BTC mistura de fontes derivadas do manto com diferentes fontes infracrustais provenientes de uma crosta continental paleoproterozóica. Participação de fontes sedimentares supracrustais é mais indicada nas rochas da USR do BCP.

Os dados geológicos apresentados sugerem que as principais diferenças litoquímicas e isotópicas entre as rochas graníticas dos dois batólitos, a exemplo do enriquecimento em $\mathrm{K}_{2} \mathrm{O}$ nas rochas do $\mathrm{BCP}$ e das diferenças nos isótopos de $\mathrm{Nd}$, Sr e Pb, seriam decorrentes das composições químicas e isotópicas distintas das fontes mantélicas e crustais e dos diferentes graus de participação dessas fontes durante a formação das rochas plutônicas do BCP e BTC, em ambiente de arco magmático continental.

Novos trabalhos de mapeamento geológico, petrológico e geocronológico das rochas graníticas do BCP e BTC estão em andamento (projeto de doutorado do primeiro autor) e devem adicionar novas e importantes contribuições geológicas sobre as rochas graníticas do BCP e do BTC.

\section{AGRADECIMENTOS}

Os autores agradecem às instituições de fomento à pesquisa CAPES e FAPESP (processo 01/00962-0) pelo apoio financeiro. Ao Centro de Pesquisas Geocronológicas do IGc/USP (CPGeo) e aos revisores pelas críticas e sugestões.

\section{REFERÊNCIAS BIBLIOGRÁFICAS}

ALMEIDA, F. F. M.; AMARAL, G.; CORDANI, U. G.; KAWASHITA, K. (1973) The precambrian evolution of the South American cratonic margin South of Amazon River. In: NAIRN, E.M.; STEHLI, F.G. (eds.) The ocean basins and margins. New York, Plenun. v.1, p. 411-446.

ALMEIDA, F. F. M.; BRITO NEVES, B. B.; CARNEIRO, C. D. R. (2000) The origin and evolution of the South American Plataform. Earth Science Reviews, v. 50, p. 77-111.

BASEI, M. A. S.; SIGAJR., O.; SATO, K.; SPROESSER, W. M. (1995) A metodologia Urânio-Chumbo na Universidade de São Paulo: princípios metodológicos, aplicações e resultados obtidos. Anais da Academia Brasileira de Ciências, v. 67, n. 2, p. 221-237.

BASEI, M. A. S.; SIGAJR., O.; REIS NETO, J. M.; HARARA, O. M.; PASSARELLI, C. R.; MACHIAVELLI, A. (1997) Geochronological map of the Precambrian terrains of Paraná and Santa Catarina States, southern Brazil: Tectonic Implications. In: SOUTH-AMERICAN SYMPOSIUM ON ISOTOPE GEOLOGY, Campos do Jordão, São Paulo, 1997. Extended Abstracts. São Paulo, SSAGI. p. 44-46.

BASEI, M. A. S. (2000) Geologia e modelagem geotectônica dos terrenos Pré-Cambrianos das regiões Sul-Oriental brasileira e uruguaia: possíveis correlações com províncias similares do sudeste africano. São Paulo, 124 p. Tese (Livre-Docência) - Instituto de Geociências, Universidade de São Paulo.

BASEI, M. A. S.; SIGA JR, O.; KAULFUSS, G. A.; CORDEIRO, H.; SATO, K.; CURY, L. F.; PRAZERES FILHO, H. J.; PASSARELLI, C. R.; HARARA, O. M. M.; REIS NETO, J. M. (em preparação). Magmatismo básico 
mesoproterozóico no Vale do Ribeira - implicações na idade de deposição das seqüências metavulcanosedimentares Perau e Votuverava, Estado do Paraná, Brasil.

BERGMANN, M. (1988) Caracterização estratigráfica e estrutural da seqüência vulcano-sedimentar do Grupo São Roque na região de Pirapora do Bom Jesus - Estado de São Paulo. São Paulo, 164 p. Dissertação (Mestrado) - Instituto de Geociências, Universidade de São Paulo.

BIONDI, J. C. (1983). Mapa geológico da área do embasamento do Estado do Paraná, escala 1:250.000. MINEROPAR, Curitiba.

CAMPANHA, G. A. C.; SADOWSKI, G. R. (1999) Tectonics of the southern portion of the Ribeira Belt (Apiaí) Domain. Precambrian Research, v. 98, p. 31-51.

CAMPANHA, G. A. C.; BISTRICHI, C. A.; ALMEIDA, M.A. (1987) Considerações sobre a organização litoestratigráfica da Faixa de Dobramentos Apiaí. In: SIMPÓSIO SUL-BRASILEIRO DE GEOLOGIA, 3., Curitiba, 1987. Atas. Curitiba, SBG, v. 2, p.725-742.

CAMPOS NETO, M. C.; FIGUEIREDO, M. C. H. (1995) The Rio Doce Orogeny, southeastern Brazil. Journal of South American Earth Sciences, v. 8, n. 2, p. 143-162.

CAMPOS NETO, M. C. (2000). Orogenic systems from Southwestern Gondwana: na approach to Brasiliano-Pan African cycle and orogenic collage in southeastern Brazil. In: CORDANI, U. G; MILANI, E. J.; THOMAS FILHO, A.; CAMPOS, D.A.. Tectonic evolution of South America. Rio de Janeiro. p. 335-365.

CHIODI FILHO, C.; MORETZSHON, J. S.; SANTOS, J. F.; SOARES, P. C. (1987) Aspectos geológicos e metalogenéticos dos granitos Morro Grande, Piedade e Varginha-Vale do Ribeira-Paraná. In: SIMPÓSIO SULBRASILEIRO DE GEOLOGIA, 3., Curitiba, 1987. Anais. Curitiba, SBG. v. 2, p. 515-542.

COMPANHIADEPESQUISADE RECURSOS MINERAISCPRM. (1977) Projeto Leste do Paraná : relatório final de Geologia - Folhas: SG-22-X-B-IV, SG-22-X-B-V, SG22-X-A-VI, SG-22-X-C-III, SG-22-X-D-I. São Paulo. DNPM/CPRM.

CORDANI, U. G.; SATO, K. (1999) Crustal evolution of the South American Platform, based on Nd isotopic systematics on granitoid rocks. Episodes, v. 22, n. 3, p.167-173.

DEPAOLO, D. J.; WASSERBURG, G. J. (1979) Petrogenetic mixing models and Nd-Sr isotopic patterns. Geochimica et Cosmochimica Acta, v. 43, p. 615-627.

FIORI, A. P. (1990) Tectônica e estratigrafia do Grupo Açungui a norte de Curitiba. São Paulo, 246 p.Tese (Li-
vre-Docência) - Instituto de Geociências, Universidade de São Paulo.

FUCK, R. A.; MARINI, O. J.; TREIN, E. (1967) Contribuição ao estudo das rochas graníticas do Estado do Paraná. Boletim Paranaense de Geociências, v. 23-25, p. 183-221.

GIMENEZ FILHO, A. G. (1993) Evolução do Complexo Três Córregos a noroeste de Apiaí - SP. São Paulo, 118 p. Dissertação (Mestrado) - Instituto de Geociências, Universidade de São Paulo.

GIMENEZFILHO, A. G; TEIXEIRA, W.; FIGUEIREDO, M. C. H.; TREVIZOLI JR, L. (1995) Geologia, petrografia, e litogeoquímica do Complexo Granítico Três Córregos na região de Barra do Chapéu e Ribeirão Branco, SP. Revista Brasileira de Geociências, v. 25, n. 2, p. 92-106.

GIMENEZ FILHO, A. G.; JANASI, V. A; CAMPANHA, G. A C.; TEIXEIRA, W.; TREVIZOLI Jr., L. E. (2000) U-Pb dating and $\mathrm{Rb}$-Sr isotope geochemistry of the Eastern portion of the Três Córregos Batolith Ribeira Fold Belt, São Paulo, Brazil. Revista Brasileira de Geociências, v. 30, n. 1, p. 45-50.

GORAIEB, C. L. (2001) Contribuição à gênese do depósito primário polimetálico $(\mathrm{Sn}, \mathrm{W}, \pm \mathrm{Zn}, \mathrm{Cu}, \mathrm{Pb})$ Córreas, Ribeirão Branco (SP). São Paulo, 215p. Tese (Doutorado) - Instituto de Geociências, Universidade de São Paulo.

GUIMARÃES, G. B. (1995) O complexo granítico Cunhaporanga na região de Joaquim Murtinlio, Piraí do Sul $(P R)$ : caracterização faciológica das rochas granitóides. São Paulo, 144 p. Dissertação (Mestrado) Instituto de Geociências, Universidade de São Paulo.

GUIMARÃES, G.; ULBRICH, H. H. G. J. (1999) Aspectos geoquímicos das rochas granitóides do complexo granítico Cunhaporanga, Sul do Brasil. In: CONGRESSO BRASILEIRO DE GEOQUIMICA, 7., Porto Seguro, 1999. Anais. Porto Seguro, SBGq, p. 522-524.

GUIMARÃES, G. B. (2000) As rochas granitóides do complexo granítico Cunhaporanga, PR: aspectos geológicos, geofísicos, geoquímicos e mineralógicos. São Paulo, 230 p. Tese (Doutorado) - Instituto de Geociências, Universidade de São Paulo.

HACKSPACHER, P. C.; DANTAS, E. L.; SPOLADORE, A.; FETTER, A. H.; OLIVEIRA, M.A. F. (2000) Evidence for neoproterozoic back arc basin development in the central Ribeira Belt, southeastern Brazil: new geochronological and geochemical constraints from the São RoqueAçungui Groups. Revista Brasileira de Geociências, v. 30, n. 1, p. 110-114.

HARARA, O. M.M. (2001) Mapeamento e investigação petrológica e geocronológica dos litotipos da região 
do Alto Rio Negro (PR-SC): um exemplo de sucessivas e distintas atividades magmáticas durante o Neoproterozóico III. São Paulo, 206p. Tese (Doutorado) - Instituto de Geociências, Universidade de São Paulo.

IRVINE, T. N.; BARAGAR, W. R. A. (1971) A guide to the chemical classification of the common volcanic rocks. Canadian Journal of Earth Sciences, v. 8, p. 523-548.

JANASI, V. A.; VASCONCELLOS, A. C. B. C.; VLACH, S. F. R.; MOTIDOME, M. J. (1990) Granitóides da região entre as cidades de São Paulo e Piedade (SP): faciologia e contexto tectônico. In: CONGRESSO BRASILEIRO DE GEOLOGIA, 36., Natal, 1990. Anais. Natal, SBG, v. 4, p. 1925-1935.

JANASI, V. A.; LEITE, R. J.; VAN SCHMUS, W. R. (2001) U$\mathrm{Pb}$ chronostratigraphy of the granitic magmatism in the Agudos Grandes Batholith (west of São Paulo) - implications for the evolution of the Ribeira Belt. Journal of South American Earth Sciences, v. 14, p. 363-376.

JULIANI, C.; HACKSPACHER, P. C.; DANTAS, E. L.; FETTER, A. H. (2000) The mesoproterozoic volcano-sedimentary Serra do Itaberaba Group of central Ribeira Belt: implications for the age of overlying São Roque Group. Revista Brasileira de Geociências, v. 30, n. 1, p. 82-86.

LEITE, R. J. (1997) Geologia, petrografia e geoquímica dos granitos da região de Piedade (SP). São Paulo, 138 p. Dissertação (Mestrado) - Instituto de Geociências, Universidade de São Paulo.

LEITE, R. J. (2003) Petrogênese e geocronologia $U-P b d o$ magmatismo granítico tardi a pós-orogênico no Batólito Agudos Grandes - SP. São Paulo, 218 p. Tese (Doutorado) - Instituto de Geociências, Universidade de São Paulo.

LEITE, J. D.; HATMANN, L. A.; MCNAUGHTON, N.; CHEMALLE JR., F. (1998) Shrimp U-Pb zircon geochronology of Neoproterozoic juvenile and crustal reworked terranes in southernmost Brazil. International Geology Reviews, v. 40, p. 688-705.

MANIAR, P. D.; PICCOLI, P.M. (1989) Tectonic discrimination of granitoids. Geological Society of America Bulletin, v. 101, p. 635-643.

MEZGER, K.; KROGSTAD, J. (1997) Interpretation of discordant $\mathrm{U}-\mathrm{Pb}$ in zircon ages: an evolution. Journal of Metamorphic Geology, v. 15, p. 127-140.

MIDDLEMOST, E. A. K. (1975) The basalt clan. Earth Science Reviews, v. 11, p. 337-364.

PEARCE, J. A.; HARRIS, N. B. W.; TINDLE, A. G. (1984) Trace element discrimination diagrams for the tectonic interpretation of granitic rocks. Journal of Petrology, v. 25 , n. 4 , p. $956-983$.
PEARCE, J. A. (1996) Sources and settings of granitic rocks. Episodes, v. 19, n. 4, p.120-125.

PICANÇO, J. L. (2000) Composição isotópica e processos hidrotermais associados aos veios auríferos do maciço granítico Passa Três, Campo Largo, PR. São Paulo, 166 p. Tese (Doutorado) - Instituto de Geociências, Universidade de São Paulo.

PIDGEON, R. T.; BOSCH, D.; BRUGUIER, O (1996) Inherited zircon and titanite U-Pb system in an Archean syenite from Southwestern Australia: implications for U-Pb stability of titanite. Earth and Planetary Science Letters, v. 141, p. 187-198.

PIMENTEL, M. M.; FUCK, R. A. (1992) Neoproterozoic crustal accretion in central Brazil. Geology, v. 20, n. 4, p. 375-379.

PIMENTEL, M. M.; FUCK, R.; ALVARENGA, C. J. S. (1996) Post-Brasiliano (Pan-African) high-K granitic magmatism in Central Brazil: the roloe of late precambriam-early paleozoic extension. Precambrian Research, v. 80, p. 217-238.

PRAZERES FILHO, H. J. (2000) Litogeoquímica, geocronologia $(\mathrm{U}-\mathrm{Pb})$ e geologia isotópica dos complexos graníticos Cunhaporanga e Três Córregos, Estado do Paraná. São Paulo, 180 p. Dissertação (Mestrado) -Instituto de Geociências, Universidade de São Paulo.

PRAZERES FILHO, H. J.; BASEI, M. A. S.; HARARA, O. M.; PASSARELLI, C. R.; SIGA JR., O.; REIS NETO, J. M.; SATO, K. (2001) The Alto Ribeira Magmatic Arc (Paraná State-Southern Brazil): geochemical and isotopic evidences of magmatic focus migration and its tectonic implications. In: SOUTH AMERICAN SYMPOSIUM ON ISOTOPE GEOLOGY, 3., Pucón, 2001. Extend Abstract. Pucón, Sociedad Geológica de Chile, p. 213-216. (CD-ROM).

REIS NETO, J. M. (1994) Faixa Itaiacoca: registro de uma colisão entre dois blocos continentais no Neoproterozóico. São Paulo, 253 p. Tese (Doutorado) Instituto de Geociências, Universidade de São Paulo.

RICKWOOD, P. (1989) Boundary lines within petrologic diagrams which use oxides of major and minor elements. Lithos, v. 22, p. 247-263.

RODDICK, J. C.; BEVIER, M. L. (1995) U-Pb dating of granites with inherited zircon: conventional and ion microprobe results from two paleozoic plutons, Canadian Appalachians. Chemical Geology, v. 119, p. 307-329.

ROGERS, G.; DEMPSTER, T. J.; BLUCK, B. J.; TANNER, P. W. G. (1989) A high precision U-Pb age for the bem vuirich granite: implications for the evolution of the Scottish 
Dalradian Supergroup. Journal Geological Society of London, v. 146, p. 789-798.

SANTOS, M. S.; FELIPE, R. S. (1980) Reconhecimento geológico da Faixa Três Córregos. Curitiba, Mineropar (Relatório Interno).

SATO, K.; TASSINARI, C. C. G.; KAWASHITA, K.; PETRONILHO, L. (1995) O método geocronológico SmNd no IG/USP e suas aplicações. Anais da Academia Brasileira de Ciências, v.67, n. 3, p.315-336.

SIGA Jr., O.; BASEI, M.A.S.; REIS NETO, J.M.; MACHIAVELLI, A.; HARARA, O.M. 1995. O complexo Atuba: um cinturão paleoproterozóico intensamente retrabalhado no neoproterozóico. Boletim IG-USP. Série Científica, v. 26, p. 69-98.

SIGA Jr. O. (1995) Domínios tectônicos do sudeste do Paraná e nordeste de Santa Catarina: geocronologia e evolução crusta. São Paulo, 212 p. Tese (Doutorado) - Instituto de Geociências, Universidade de São Paulo.

SIGAJR, O.; BASEI, M. A. S.; WEBER, W.; SATO, K.; REIS NETO, J. M.; PRAZERES FILHO, H. J.; NUTMAN, A. P. (2001) The Itaiacoca Group: U-Pb (zircon) records of a Neoproterozoic Basin: In: SOUTH AMERICAN SYMPOSIUM ON ISOTOPE, 3., Pucón, 2001. Extended Abstract. Pucón, Sociedad Geológica del Chile, p.245-248. (CD-ROM)

SIGAJR. O.; BASEI, M.A. S.; SATO, K.; PRAZERES FILHO, H. J.; CURY, L.F.; WEBER, W.; PASSARELLI, C. R.; HARARA, O. M.; REIS NETO, J. M. (no prelo) U-Pb (zircon) ages of metavolcanic rocks from the Itaiacoca Group: tectonic implications. Boletim IGc-USP. Série Cientifica.

STRECKEISEN, A. (1976) To each rock its proper name. Earth Science Reviews, v. 12, p. 1-33.

UNRUG, R. (1996) The assembly of Gondwanaland. Episodes, v. 19, n. 1-2, p.11-20.

WEBER, W.; SIGA JR, O.; SATO, K.; REIS NETO, J. M.; BASEI, M. A. S.; NUTTMAN, A. ((no prelo) A Formação Água Clara na região de Araçaíba - SP: registro U-Pb de uma bacia mesoproterozóica. Boletim IG-USP. Série Científica.

WERNICK, E.; RIGO JR., L.; GALEMBECK, T. M. B.; WEBER-DIEFENBACH, K. (1990) Os complexos granitóides Cunhaporanga e Três Córregos (PR): zoneamento magmático e implicações geotectônicas. Geociências, v. 9, p. 67-85.

ZARTMAN, R. E.; DOE, B. R. (1981) Plumbotectonics-the model. Tectonophysics, v. 75, n. 1-2, p.135-162. 